\title{
1 Structures of FHOD1-Nesprin1/2 complexes reveal alternate binding modes for the FH3
}

\section{2 domain of formins}

3

4 Sing Mei Lim¹, Victor E. Cruz ${ }^{1}$, Susumu Antoku², Gregg G. Gundersen², Thomas U. Schwartz ${ }^{1, *}$ 5
${ }^{1}$ Department of Biology, Massachusetts Institute of Technology, Cambridge, Massachusetts 02139, USA

${ }^{2}$ Department of Pathology and Cell Biology, Columbia University, New York, New York 10032, USA

\section{ABSTRACT}

The nuclear position in eukaryotic cells is controlled by a nucleo-cytoskeletal network, with important roles in cell differentiation, division and movement. Forces are transmitted through conserved linker of nucleoskeleton and cytoskeleton (LINC) complexes that traverse the nuclear envelope and engage on either side of the membrane with diverse binding partners. Nesprin-2 giant (Nes2G), a LINC element in the outer nuclear membrane, connects to the actin network directly as well as through FHOD1, a formin whose major activity is bundling actin. Much of the molecular details of this process remain poorly understood. Here, we report the crystal structure of Nes2G bound to FHOD1. We show that the G-binding domain of FHOD1 is rather a spectrin repeat binding enhancer for the neighboring FH3 domain, possibly establishing a common binding mode among this subclass of formins. The FHOD1-Nes2G complex structure suggests that spectrin repeat binding by FHOD1 is likely not regulated by the DAD helix of FHOD1.

4 Finally, we establish that Nes1G also has one FHOD1 binding spectrin repeat, indicating that 25 these abundant, giant Nesprins have overlapping functions in actin-bundle recruitment for 6 nuclear movement. 
bioRxiv preprint doi: https://doi.org/10.1101/2020.06.19.161299; this version posted June 20, 2020. The copyright holder for this preprint (which was not certified by peer review) is the author/funder, who has granted bioRxiv a license to display the preprint in perpetuity. It is made available under aCC-BY 4.0 International license. 


\section{INTRODUCTION}

29 Eukaryotic cells in multicellular organisms display an enormous range of specialization. The

30 development of different tissues coincides with cellular reorganization, particularly of the

31 elaborate organellar structure. The position of the nucleus as the largest organelle is often found

32 to be a distinct marker for certain cell types, for example in muscle cells or in neurons ${ }^{1}$. During

33 nuclear migration, the nucleus interacts with the cytoskeletal network for active positioning.

34 Pulling forces across the nuclear envelope are mediated by a two-protein complex known as

35 Linker of Nucleoskeleton and Cytoskeleton (LINC) ${ }^{2,3}$. LINC complexes are universally

36 conserved in eukaryotes and consists of Nesprins (Nuclear envelope spectrin repeat proteins)

37 that transverse the outer nuclear membrane (ONM), and Sad1-UNC84 (SUN) proteins which

38 pinch through the inner-nuclear membrane (INM) and connect to the nucleoskeleton. In the

39 perinuclear space, three SUN domains interact with three C-terminal KASH peptides of

40 Nesprins to form an intricate heterohexameric assembly ${ }^{4}$, the core of the LINC complex.

41 Humans have five known SUN proteins and six KASH-containing ONM proteins. Some of these

42 SUN- and KASH-proteins are ubiquitously expressed, while some are tissue specific. They

43 generate a diverse network of nucleo-cytoplasmic linkages that are important for homeostasis

44 and trigger multiple genetic diseases, if altered ${ }^{5-7}$. The regulation and the interplay between

45 the different LINC complexes is an important element in deciphering the entire network.

46 In the migrating fibroblasts, the nuclear position depends on nesprins-2 giant (Nes2G), a large,

47 actin-binding LINC component of transmembrane actin-associated (TAN) lines ${ }^{8}$. FHOD1 is a

48 formin that itself binds and bundles actin, while also interacting with Nes $2 \mathrm{G}^{9}$. This way, an

49 interaction network between actin bundles, Nes2G, and FHOD1 is established.

50 The molecular details of this intricate connection are largely unknown, in no small part because

51 the proteins involved are complicated, multi-domain entities. The $800 \mathrm{kDa}$ Nes2G contains two

52 N-terminal, actin-interacting calponin homology $(\mathrm{CH})$ domains followed by 56 spectrin repeats 
53 (SRs) before the ONM-transversing transmembrane-helix and the C-terminal KASH peptide,

54 that interacts with SUN1/2 $2^{10,11}$. Formins are categorized into several classes dependent on their

55 function and domain architecture ${ }^{12-15}$. FHOD1 is the founding member of one class, with an N-

56 terminal, presumed G-protein binding domain (G2 or GBD2), followed by an FH3 or diaphanous

57 inhibitory domain (DID) that is autoinhibited through a conserved C-terminal diaphanous-

58 autoregulatory domain $(D A D)^{16}$. Between FH3 and DAD, FHOD1 also contains a dimerization

59 motif and the actin-bundling $\mathrm{FH} 2$ domain, central to all formins ${ }^{12,17}$. Another large class of

60 formins are the diaphanous-related formins (DRFs). They contain a tested, structurally different

61 GBD N-terminal to the $\mathrm{FH}^{18,19}$.

62 We sought to advance our mechanistic understanding of the emerging, functionally important

63 actin-Nes2G-FHOD1 network. In this study, we determined the crystal structure of Nes2G-

64 SR11/12 in complex with FHOD1, revealing a novel formin-binding motif within spectrin repeats.

65 Using a bioinformatic analysis we detect that Nes $1 \mathrm{G}$ also carries this formin-binding motif in one

66 out of its 76 SRs, which we confirm with structural and biochemical methods. SR11/12 binding

67 by FHOD1 is outside of the autoregulation through DAD and independent of actin bundling.

68 Further, we establish that the small domain preceding the FH3 domain of FHOD1, formerly

69 GBD2 or G2, is in fact a modulator of the binding specificity of the neighboring FH3 domain, 70 making the paired domain specific for SR, rather than GTPase interaction.

\section{RESULTS}

\section{Crystal structure of Nesprin2G-SR11/12 in complex with FHOD1-N}

75 We set out to characterize how Nes2G interacts with the N-terminal GBD-FH3 domain element 76 of FHOD1 structurally. This is based on a previous study where specific Nes2G SRs and

77 FHOD1 domain domains have been identified ${ }^{9}$. We recombinantly expressed spectrin repeats 
SR 11-12 of human Nes2G (residues 1425-1649) as well as FHOD1-N (residues 1-339) (Figure $1 \mathrm{a})^{20}$. Both proteins form a stable 1:1 complex, with a measured $\mathrm{K}_{\mathrm{D}}$ of $375 \mathrm{nM}$ (Supplementary

fig. 1). While we initially worked with a cysteine double-mutant, FHOD1-N (C31S C71S), based

on the report that wildtype FHOD1-N have a tendency to form artificial, cysteine-mediated

82 dimers in solution ${ }^{20}$. We did not observe the reported behavior (Supplementary fig. 2). Therefore,

83 we continued our studies with wildtype FHOD1-N.

We obtained crystals of the Nes2G-SR11/12-FHOD1-N that diffracted to $2.8 \AA$ resolution. The

crystals belong to space group C2 and contain two heterodimeric complexes per asymmetric

87 unit. One of the two complexes is better packed and therefore better resolved. Both complexes superpose well with a root mean square deviation (RMSD) of $0.82 \AA$. Nes2G-SR11/12 adopts the canonical structure of a tandem spectrin repeat (SR), i.e. two antiparallel coiled-coils connected by a continuous $\alpha$-helix, generating two tethered three-helix bundles with a left-

91 handed twist (Figure 1b). FHOD1-N superposes well with the apo-structure ${ }^{20}$ with an RMSD of

$921.08 \AA$. The FH3 domain (residues 115-339) is an a-helical solenoid composed of five armadillo

93 repeats. It is immediately preceded by a small domain (residues 14-114) that has a ubiquitin

94 superfold. Formerly described as a GTPase-binding domain, we refer to this domain as an SR-

95 binding module (SRBM), as it will become clear further on. The most significant difference 96 between apo- and Nes2G-bound FHOD1-N is the ordering of a surface loop in the SRBM 97 domain, residues 30-40, upon binding.

99 FHOD1-N engages with the tandem SR repeat by generating a continuous binding surface 100 along the long axis of the helical bundle. In total, the binding interface buries $1191 \AA^{2}$. The 101 majority of the interaction is between the FH3 domain and SR12, with additional contributions 102 from the SRBM and the long, SR11/SR12 connecting central helix. As it is typical for protein- 
103 protein interactions, we see a mix of van der Waals, polar and charged interactions throughout

104 the interface. Two areas within the binding interface stand out, referred to as site A and site B

105 (Figure $1 \mathrm{~b}-\mathrm{e}$ ). Site $\mathrm{A}$ is the core interface, centered around a remarkable charge network.

106 D1625, D1629, and E1632 of Nes2G-SR12 form a web of salt bridges with R136 and R137 of

107 FHOD1-N (Figure 1c). The hydrophobic residues L1628 of Nes2G-SR12 and F140 of FHOD1-N

108 get deeply buried in the site A interface upon binding. A number of additional hydrogen-bonds

109 surround and complete this site (Figure 2). All the key residues in site A are very well conserved

110 across diverse species, supporting the notion that this is an important functional interface

111 (Figure 2).

113 Site B involves the loop connecting strands $\beta 1$ and $\beta 2$ of FHOD1-SRBM, particularly residues

114 30-38, interacting primarily with the very N-terminal a-helical element Nes2G-SR12 (residues

115 1525-1532). The FHOD1-SRBM-loop packs against the SR12 helical bundle and becomes well-

116 ordered, in contrast to its more flexible position in the apo-form. A hydrogen-bonding / charge

117 network is formed between E36 and R38 of FHOD1-SRBM and E1528 and Q1529 of Nes2G-

118 SR12, with the best ordered water molecule of the structure as an integral component (Figure

119 1e). Several exposed, hydrophobic residues get buried upon binding (A32, F34 of FHOD1-

120 SRBM and F1603 of Nes2G-SR12) (Figure 2).

\section{Mutations in Nes2G-FHOD1 interface residues abolish protein complex formation}

123 In order to determine which residues are most critical for the interaction, and to generate

124 meaningful point-mutations for biological assays, we analyzed the effect of mutating conserved

125 interacting residues. We probed for complex formation by size exclusion chromatography (SEC)

126 and bio-layer interferometry (BLI) (Figure 3). In site A, we determined that the charge network is

127 essential for binding, since a Nes2G-SR11/12 D1625A/D1629A double mutant abolished

128 binding in the SEC assay. Mutating the paired, charged residues on FHOD1-N, R136A and 
129 R137A, expectedly, has the same effect (Figure 3b - d). The hydrophobic interaction between

130 Nes2G-SR11/12 L1628 and FHOD1-N F140 is also essential. A Nes2G-SR11/12 L1628R or

131 Nes2G-SR11/12 L1628A/E1632A mutant abolishes binding as well (Figure 3a \& c). We also

132 analyzed site $B$, probing it with a FHOD1-N SRBM-loop triple mutant E36A/P37G/R38A. SEC

133 and BLI both still show residual binding, suggesting that site B is perhaps somewhat less critical

134 than site A (Figure 3b - d). In summary, we establish Nes2G-D1625A/D1629A and FHOD1-

$135 \mathrm{R} 136 \mathrm{~A} / \mathrm{R} 137 \mathrm{~A}$ as structurally defined, non-interacting probes for in vitro and in vitro studies.

\section{FHOD1-mutations in Nes2G interface block nuclear migration}

138 It is known that FHOD1 and Nes2G functionally interact in the context of nuclear migration ${ }^{21,22}$.

139 We tested the FHOD1-R136A/R137A mutant in a nuclear movement assay. In the assay,

140 wounded monolayers of serum-starved fibroblast cells are stimulated by lysophosphatidic acid

141 (LPA), resulting in rearward movement of the nucleus away from the wounded cell edge. We

142 depleted endogenous FHOD1 in NIH3T3 fibroblast using a shRNA approach, which resulted in

143 nuclear movement defects that can be rescued by the expression of wildtype FHOD1 (Figure 4a

144 - c). In contrast, we see hardly any rescue using the FHOD1-R136A/R137A. The result is a

145 phenocopy of FHOD1-1705A mutant which inactivates actin barbed-end binding ${ }^{23}$. This

146 experiment demonstrated that the direct FHOD1-Nes2G contact is critical for nuclear migration.

148 The FHOD1 binding motif is also found in Nesprin1-Giant

149 Having established how FHOD1-N interacts with Nes2G-SR11/12 we asked whether the motif

150 we identified might be found in other spectrin repeat proteins as well. Based on our mutational

151 study, we identified DxWLD[IVLA]XE to be a signature motif within a spectrin repeat that would 152 suggest FHOD1-binding . By using BLAST pattern search, we found this motif in one other 153 spectrin repeat containing actin binding protein, namely Nesprin1-Giant (Nes1G). Nes1G is also 
154 part of LINC complexes, with a C-terminal KASH-peptide that interacts with Sun1/2. Similar to

155 Nes2G, the $\mathrm{N}$ terminus of Nes1G has two actin-binding $\mathrm{CH}$ domains followed by many (74 vs 56)

156 SRs (Duong et al., 2014). We found the motif, 100\% conserved, in Nes1G-SR18 (Figure 5a).

157 To test the functionality of Nes1G-SR18 as an FHOD-1 interactor, we expressed and purified

158 the tandem SR repeat Nes1G-SR17/18 (residues 1976-2200) recombinantly in E. coli and

159 analyzed FHOD1-N binding by SEC and BLI. FHOD1-N and Nes1G-SR17/18 coelute from a

160 SEC column as a complex with 1:1 stoichiometry (Figure 5b). We measured a binding affinity

161 between Nes1G-SR17/18 and FHOD1-N of 85 nM, comparable to that of Nes2G-SR11/12 under

162 the same buffer condition (Figure 5c). Further pointing to the same binding interaction, when the

163 aspartate residues were mutated in the DxWLD[IVLA]xE motif or the corresponding

$164 \mathrm{R} 136 \mathrm{~A} / \mathrm{R} 137 \mathrm{~A}$ mutations introduced into FHOD1-N, Nes1G-SR17/18 no longer binds to

165 FHOD1-N (Figure 5d, e).

167 Structure of Nes1G-SR17/18 with FHOD1-N

168 We obtained crystals of Nes1G-SR17/18 in complex with FHOD1-N that diffracted to $7 \AA$ 169 resolution. The structure was solved by molecular replacement using the Nes2G-SR11/12-

170 FHOD1-N complex as the search model. The crystals also belong to the C2 space group, with

171 two complexes per asymmetric unit. Due to the modest resolution, we only used rigid body

172 refinement to position the four domain elements, Nes1G-SR17, Nes1G-SR18, FHOD1-SRBM,

173 and FHOD1-FH3. Nes1G-SR17 is essentially invisible in the density, suggesting disorder

174 (Figure 6a, Supplementary fig. 3). The other three domain element superpose very well with the

175 Nes2G-SR12-FHOD1-N complex. In order to verify whether SR17 is dispensable for FHOD1-N

176 interaction, we analyzed a Nes1G-SR18-only construct (residues 2076-2200) for FHOD1-N

177 binding. We found stable FHOD1-N interaction with Nes1G-SR18 as analyzed by SEC and BLI

178 (Figure 6 b,c). 


\section{Binding of Nes2G does not preclude FHOD1-autoinhibition}

181 Actin bundling by FHOD1-N is autoinhibited by its C-terminal DAD-helix binding to the FH3

182 domain. This autoinhibition can be released by phosphorylation of various serine and threonine 183 residues within the DAD-helix by Rho dependent kinase ${ }^{24}$. Since both, Nes2G-SR $11 / 12$ and 184 DAD, can bind to the FH3 domain, we tested whether they compete with one another. While the 185 DAD binding site is not structurally known for FHOD1, it can be predicted with great confidence. 186 The superposition of the FH3 domain of mDia bound to its DAD-helix (PDB code 2F31) onto 187 FHOD1-FH3 suggests a position, that is functionally confirmed by mutational analysis. A V228E 188 mutation on the surface of FHOD1-FH3, predicted to be in the core of the DAD-binding site, 189 potently blocks DAD-binding in vitro ${ }^{20}$. Modelling a putatively bound DAD-helix onto our Nes2GSR11/12-FHOD1-N complex suggests that the two interactions are independent and not in 191 steric conflict (Figure 7a). To test this experimentally we co-incubated Nes2G-SR11/12-FHOD1$192 \mathrm{~N}$ complex with an MBP-tagged 3C-cleavable DAD-helix fusion. To avoid steric hindrance by 193 the MBP-fusion tag we added 3C protease. As expected, we detect DAD-helix coeluting with the 194 Nes2G-SR11/12-FHOD1-N complex, indicating that the two binding sites are independent 195 (Figure 7b). It further suggests that FHOD1 autoinhibition does not regulate Nes1G or Nes2G 196 binding 25,26 domain

200 Phylogenetic analysis revealed that the FH3 or DID domain in formins is preceded by one of two 201 small domains. either a GTPase-binding domain (GBD or G) or the SRBM described here 202 (formerly GBD2 or G2). Several crystal structures of the tethered GBD-FH3 domain in complex 203 with small GTPases exist from diverse species, and the binding mode is very similar. Both the 
204 GBD domain and the FH3 domain contribute to the GTPase interaction (Figure $8 a)^{18,19}$. In

205 comparison, the tethered SRBM-FH3 domain instead binds SRs, also with contributions from

206 both domain elements (Figure 8b). When we phylogenetically analyzed maximally diverged

207 SRBM-FH3 sequences and compared them with equally diverged GBD-FH3 sequences we

208 detected distinct conservation of key residues within the respective binding sites of the $\mathrm{FH} 3$

209 domain (Figure 8). For example, positions 144 and 189 of FHOD1, strongly conserved as

210 glutamine and leucine, respectively, in the SRBM-FH3 family, are instead strongly conserved as

211 valine and asparagine in the GBD-FH3 family (Supplementary fig. 3D). Conversely, the pair of

212 invariant arginines in position 136 and 137 of FHOD1, important for SR recognition, are not at

213 all conserved in the GBD-FH3 family (Supplementary fig. 3H). This result clearly suggests that

214 the FH3 domain has evolved to either bind a small GTPase or SRs, depending on which domain,

215 SRBM or G, it is tethered to. In other words, SRBM or G modulate the binding activity of the

216 neighboring $\mathrm{FH} 3$ domain.

\section{DISCUSSION}

220 Here we show how FHOD1-N engages with SRs from two nesprins to form stable complexes.

221 How does this structure inform us about tethering between the nucleus and actin bundles during

222 nuclear migration along TAN lines? One important factor is how to achieve stability within this

223 protein network. We propose that this is established through a multitude of interactions with

224 actin. Specifically, Nesprin2 has two $\mathrm{N}$-terminal $\mathrm{CH}$ domains each of which directly bind actin

225 filaments. Furthermore, SR11/12 engages with FHOD1, which bundles actin through its $\mathrm{FH} 2$

226 domain. Since FHOD1 itself is a dimer, this tethered FHOD1-Nes2G heterotetrameric unit then

227 already has 6 individual actin binding sites (Figure 9a). Due to avidity, this arrangement should 228 greatly increase actin filament affinity, a prerequisite for sustaining the large mechanical forces 
associated with moving such a gigantic cargo. This is also compatible with a model of Nesprins $1 / 2$ tethering together neighboring actin filaments to induce bundling in a TAN line assembly (Figure 9b) ${ }^{27}$.

232 This structure is a snapshot along the path toward understanding the entire TAN line network.

233 Much remains to be discovered to mechanistically understand the whole process of nuclear 234 migration. One important element to consider going forward is the significance of FHOD1 235 binding to primarily just one SR in both, Nes1G and Nes2G. With these giant nesprins containing 74 and 56 SRs, respectively, is there significance in the position of the interacting SR?

237 Going forward, an interesting experiment will be to shuffle the position of the FHOD1 binding 238 site within these long SR proteins and see which effect this may have. The existing data 239 strongly suggest that the position is critical. Our structures reveal that FHOD1 binds only highly 240 specific SRs, namely those with the conserved sequence motif we discovered. It explicitly does 241 not bind generic SRs. Therefore, the position of the cognate SR within a nesprin should matter.

242 An alternative hypothesis would be that the number of binding sites rather than the position 243 within a nesprin is important. This is also a testable scenario.

244 This is the first crystal structure of a nesprin SR domain and it confirms that Nes2G-SR11/12 245 shares, as expected from modeling, strong structural homology with the canonical SR 246 architecture, as seen in $\alpha$ - and $\beta$-spectrin (Supplementary Fig.5A-B). The main interaction with 247 FHOD1 is mediated through a binding interface which has a distinct sequence motif 248 DxWLD[IVLA]xE, found in Nes2G-SR12 and Nes1G-SR18, respectively. Binding by Nes1G and 249 Nes2G is very similar, except that for Nes2G the interface also includes a short element of the 250 preceding SR11. For Nes1G, SR17 is dispensable. While one could formally argue that in 251 Nes2G a tandem SR is recognized while in Nes1G a single SR is sufficient, we would consider 252 this to be an exaggeration of the actual differences. The SR11 element bound by FHOD1 is 253 merely through the shared central helix that connects SR11 and SR12 and defining the exact 
254 domain boundary between the two is to an extend somewhat arbitrary. To our knowledge, there

255 is one crystal structure of SRs with a binding partner, which is human erythroid $\beta$-spectrin bound

256 to ankyrin (PDB code $3 \mathrm{KBT})^{28}$. Here, the interface clearly spans two SRs and the authors

257 argued for the specific importance of the relative orientation of the neighboring domains. The

258 binding itself is very different from the FHOD1-SR interface, which is not surprising given that

259 FHOD1 and ankyrin have different domain architectures.

260 We now establish that the formerly named G2 or GBD2 domain of FHOD1 is a spectrin-repeat

261 binding modulator, which we call SRBM. It is another remarkable example of how nature has

262 coopted a common domain fold, here ubiquitin, to evolve a novel function. This common theme

263 has been seen in many other folds, including helix-turn-helix motifs, $\beta$-propeller proteins, to

264 name just a few ${ }^{29,30}$. The distinct evolution of the SRBM within the larger formin family has been

265 recognized before based on phylogenetic analysis ${ }^{31}$. However, it remained nearly unchallenged

266 that this domain may not bind a small GTPase. Our work provides another powerful example for

267 why experimental validation is a critical element of discovery. Divergent evolution of domains

268 into diverse functions can be difficult to discern, especially if these functions do not correlate

269 with an easily recognizable sequence pattern.

270 The SRBM is not an autonomous domain that has its separable function. It appears to only

271 function in tandem with the neighboring FH3 domain, which is why we call it a modulator.

272 Neither FH3, nor SRBM bind a spectrin repeat independently. The sequence conservation of

273 the SRBM supports this notion. The best conserved part within the SRBM is the long loop

274 connecting $\beta 1$ and $\beta 2$, which is precisely necessary to lock the module with the $\mathrm{FH} 3$ domain

275 and also to directly bind the cognate SR. Furthermore, neighboring SRBM and FH3 domains

276 coevolved to bind spectrin repeats, which is evident when one compares the FHOD class of

277 formins (Figure 8). The situation is not very different for the bona fide GBD, which is found in the

278 larger class of diaphanous-related formins (DRFs). As shown previously, it also binds small 
279 GTPases in conjunction with the neighboring FH3 and apparently not autonomously ${ }^{18,19}$. In the

280 DRFs, the GBD co-evolved with the neighboring FH3 in much the same way as SRBM co-

281 evolved with its joint FH3. This is clearly evident in the Pfam protein family database, where the

282 GBD is defined as containing about half of the FH3 domain (Pfam entry 06371), with conserved

283 residues distributed over both structural elements. Taken together, we suggest that GBD and

284 SRBM are two, mutually exclusive modulators of the FH3 domain that direct and specify its

285 binding activity. Perhaps, it is no coincidence that the FH3 domain is an a-solenoid, a versatile

286 domain found in many, highly diverse protein assemblies.

\section{MATERIALS \& METHODS}

290 Protein expression and purification

291 Residues 1425-1649 of human Nesprin-2, corresponding to spectrin repeats 11 and 12, were 292 cloned into the bacterial expression vector pETDuet1 to generate a human rhinovirus $3 \mathrm{C}(3 \mathrm{C})$ 293 cleavable His-tag fusion protein (Nes2G-SR11/12). LOBSTR(DE3)-RIL E. coli cells (Kerafast) 294 were transformed with the expression vector and grown at $37{ }^{\circ} \mathrm{C}$ in LB medium with $0.4 \%$ (w/v) 295 glucose and in the presence of antibiotics to maintain the plasmids. Protein expression was 296 induced with $0.2 \mathrm{mM}$ isopropyl $\beta$ D-1-thiogalactopyranoside (IPTG) at OD600 $=0.7$, at which 297 point the culture was shifted to $18^{\circ} \mathrm{C}$. Cells were grown for another $12-16 \mathrm{~h}$. The cells were then 298 harvested by centrifugation at $6000 \mathrm{~g}$ for 6 mins and resuspend in $50 \mathrm{mM}$ potassium phosphate $299 \mathrm{pH} 8.0,400 \mathrm{mM} \mathrm{NaCl}, 40 \mathrm{mM}$ imidazole and $5 \mathrm{mM} \beta$-mercaptoethanol. Cells were lysed by 300 mechanical disruption with a LM-20 Microfluidizer (Microfluidics) at 18,000 psi then spun at $3019500 \mathrm{~g}$ for 25 mins. The clear supernatant was incubated with Ni-Sepharose 6 Fast Flow (GE 302 Healthcare) to capture the His-tagged protein. After batch washing in lysis buffer, the Ni-resin 303 was poured into a disposable column, drained, and the bound protein was eluted with elution 
304 buffer (10 mM Tris/HCl pH 7.5, $150 \mathrm{mM} \mathrm{NaCl,} 250 \mathrm{mM}$ imidazole, $5 \mathrm{mM} \beta$-mercaptoethanol).

305 The eluate was cleaved with 3C protease overnight and Nes2G-SR11/12 was further purified by

306 cation exchange chromatography on a HiTrap SP-FF column (GE Healthcare).

308 Similarly, the coding sequence for residues 1-339 of human FHOD1 was also cloned into the 309 pETDuet1 plasmid (wtFHOD1-N), as well as a C31S C71S double mutant (mtFHOD1-N). 310 Expression and purification were carried out as for Nes2G-SR11/12 described above. To form 311 complexes, purified Nes2G-SR11/12 and wt FHOD1-N or mt FHOD1-N were mixed in a 1 to 1

312 ratio followed by size exclusion chromatography. The protein complex eluted as a 313 monodisperse peak from a Superdex 200 gel filtration column (GE Healthcare) in $20 \mathrm{mM}$ 314 HEPES/NaOH pH 8.0, 100 mM KCl, 0.2 mM EDTA, 1 mM DTT. All remaining Nes2G-SR11/12 315 mutants ( L1628R, L1628A E1632A, D1625A D1629A) and FHOD1-N mutants ( R136A R137A, 316 E36A P37A R38A) were expressed and purified with the same protocol.

318 FHOD1 DAD domain (residue 1052-1164) preceded by maltose binding protein (MBP) and a 319 3C-cleavage site was expressed the same way. The sample in lysis buffer $10 \mathrm{mM}$ $320 \mathrm{HEPES} / \mathrm{NaOH} \mathrm{pH} 8.0,200 \mathrm{mM} \mathrm{KCl}, 5 \mathrm{mM} \beta$-mercaptoethanol was purified by affinity 321 chromatography over amylose resin. The target protein was eluted with $10 \mathrm{mM}$ maltose and 322 further purified via gel filtration on a Superdex S75 (GE Healthcare) column.

324 Three Nesprin1 constructs were generated; The first containing residue 1976 to 2200 and 325 identified as SR17/18 (Nes1G-SR17/18); the second a D2176A D2180A mutant and the third an 326 SR18 only construct (residue 2076-2200). All were cloned, expressed, and purified following 327 the method described above without substantive changes. For affinity measurements by bio- 
328 layer interferometry, Nes1G an Nes2G constructs were N-terminally tagged with an AVI

329 sequence (GLNDIFEAQKIEWHE) for biotinylation in the E. coli expression host.

331 Crystallization

332 Purified complexes of Nes2G-SR11/12 with wtFHOD1-N or mutant FHOD1-N were

333 concentrated to $7 \mathrm{mg} / \mathrm{ml}$ for sparse matrix crystallization screen. Both complexes initially 334 crystallized in $0.1 \mathrm{M} \mathrm{Tris} / \mathrm{HCl} \mathrm{pH} 8.5,0.2 \mathrm{M}$ potassium sodium tartrate, $21 \% \mathrm{PEG} 3350$ at $18{ }^{\circ} \mathrm{C}$ 335 using the hanging-drop vapor diffusion method with a $1 \mu \mathrm{L}$ well-solution to $1 \mu \mathrm{L}$ protein setup. 336 Large, rectangular-rod crystals formed within 5 days and were supplemented with $15 \%$ glycerol 337 as cryo-protectant prior to freezing. Crystals of Nes1G-SR17/18 and FHOD1-N were grown in $338 \quad 0.1 \mathrm{M} \mathrm{HEPES} / \mathrm{NaOH} \mathrm{pH} 7.0,0.2 \mathrm{M}$ sodium thiocyanate, 40\% 5/4 pentaerythritol propoxylate at $33918^{\circ} \mathrm{C}$ using the sitting drop method.

341 Data collection \& processing

342 Diffraction data were collected at the NE-CAT beamline 24-ID-C in Argonne National Laboratory

343 and processed with $\mathrm{HKL}-2000^{32}$. The structures were all solved by molecular replacement using 344 Phaser from within the PHENIX package ${ }^{33}$. The initial search model was FHOD1-N (PDB Code $3453 D A D)^{34}$. Additional helical density for the spectrin repeats was readily visible in the initial map.

346 The model was built and refined iteratively using $\mathrm{COOT}^{35}$ in combination with phenix.refine. The

347 structure of Nes1G-SR17/18 in complex with wtFHOD1-N were phased with molecular 348 replacement of the Nes2G_SR11/12 FHOD1-N complex structure. Table 1 lists the final statistics 349 for two complexes, Nes2G-SR11/12 - FHOD1-N and Nes1G-SR17/18 - FHOD-N respectively. 350

\section{Complex analysis by size exclusion chromatography}


352 Purified proteins were mixed in a 2 to 1 molar ratio, with Nes1G or Nes2G in excess, and

353 incubated on ice for $1 \mathrm{hr}$. Then, $1 \mathrm{~mL}$ of sample mixture was loaded onto a Superdex S200

354 10/300 GL gel filtration column for size analysis. The running buffer for all analytical studies was

$35520 \mathrm{mM}$ HEPES/NaOH pH 8.0, $100 \mathrm{mM} \mathrm{KCl,} 0.2 \mathrm{mM}$ EDTA, $1 \mathrm{mM}$ DTT. The chromatography

356 experiment was run at $0.5 \mathrm{ml} / \mathrm{min}$ flow rate and $500 \mu \mathrm{L}$ sample fractions were collected for SDS-

357 PAGE analysis.

\section{Bio-layer interferometry}

Interaction of Nes1G or Nes2G spectrin repeats with FHOD1 was measured by Bio-layer

361 interferometry on an 8-channel Octet RED96e system (Forté Bio). First, streptavidin biosensor

362 tips were pre-incubated with an assay buffer $(20 \mathrm{mM} \mathrm{HEPES} / \mathrm{NaOH} \mathrm{pH} 8.0,100 \mathrm{mM} \mathrm{KCl}, 0.2$

$363 \mathrm{mM}$ EDTA, $1 \mathrm{mM}$ DTT, $0.2 \%$ bovine serum albumin (BSA) and $0.01 \%$ Tween-20) for $10 \mathrm{~min}$ at

$36430{ }^{\circ} \mathrm{C}$. Then, the tips were incubated with $\mathrm{N}$-terminally biotinylated Nes1G and Nes2G

365 constructs in assay buffer to yield a loading thickness of $0.3-0.4 \mathrm{~nm}$. After washing the tips with

366 assay buffer binding to wtFHOD1-N was measured in real time by recording the increase in

367 optical thickness of the tips during an association phase. Finally, the tips were transfer back into 368 assay buffer to measure the dissociation rate. The concentration of FHOD1 was fixed at $0.4 \mu \mathrm{M}$

369 for qualitative experiment to validate the effect of mutant versus wild-type Nes1G and Nes2G

370 binding. A two-fold dilution series of FHOD1-N concentration ranging from 0.01 to $0.4 \mu \mathrm{M}$ was

371 used for measuring the binding affinity of FHOD1 and Nesprins. For data analysis we used

372 Octet Data Analysis software and transferred the processed output into GraphPad Prism 7 for

373 curve-fitting analysis by using association-dissociation non-linear regression model. 
376 Purified MBP-DAD was mixed with either wtFHOD1-N only or Nes2G-SR11/12-FHOD1-N

377 complex in a 1 to 1 molar ratio and incubated overnight in the presence of $3 \mathrm{C}$ protease. The

378 samples were analyzed by gel filtration over Superdex S75 10/300 in running buffer $20 \mathrm{mM}$

$379 \mathrm{HEPES} / \mathrm{NaOH} \mathrm{pH}$ 8.0, $100 \mathrm{mM} \mathrm{KCl}, 0.2 \mathrm{mM}$ EDTA and $1 \mathrm{mM}$ DTT. Relevant elution fractions

380 were analyzed by SDS PAGE.

382 Analytical ultracentrifugation

383 FHOD1-N (2 mg/mL) was dialyzed into $20 \mathrm{mM} \mathrm{HEPES} / \mathrm{NaOH} \mathrm{pH} 8.0,100 \mathrm{mM} \mathrm{KCl,} 0.2 \mathrm{mM}$

384 EDTA with and without $0.5 \mathrm{mM}$ Tris (2-carboxyethyl) phosphine hydrochloride (TCEP-HCl) for

385 two days in $4^{\circ} \mathrm{C}$. Samples were then prepared in $450 \mu \mathrm{L}$ with final concentrations of $0.3 \mathrm{mg} / \mathrm{mL}$,

$3860.6 \mathrm{mg} / \mathrm{mL}$ and $0.8 \mathrm{mg} / \mathrm{mL}$ for sedimentation velocity (SV) experiment. The experiment was

387 performed in an Optimal XL1 (Beckman Coulter) ultracentrifuge using the An50 Ti rotor at $20{ }^{\circ} \mathrm{C}$

388 with a rotation speed of $45,000 \mathrm{rpm}$. A total of 500 absorbance scans at $280 \mathrm{~nm}$ were acquired

389 with 1-minute intervals. Scans 1 to 50 were used for analysis in SEDFIT ${ }^{36}$.using the size

390 distribution $\mathrm{c}(\mathrm{s})$ model. SEDNTERP were used to calculate the density and viscosity of the

391 buffer at $20^{\circ} \mathrm{C}$.

\section{Plasmids for LPA stimulation experiments}

394 All constructs were confirmed by DNA sequencing. pSUPER-hygro was derived from the 395 pSUPER-puro (Oligoengine) by replacing a puromycin resistance gene sequence with a 396 hygromycin resistance gene sequence from pMSCV-hygro vector (Clontech), and it was used 397 for expressing shRNA in NIH3T3 fibroblasts by retroviral infection. pMSCV-puro EGFP-C4 398 vector was used to express EGFP tagged protein in NIH3T3 by retroviral infection. Both 399 pMSCV-puro EGFP-C4 human FHOD1 WT and I705A mutants were previously described ${ }^{23}$.

400 Human FHOD1 R136A R137A mutant was made by introducing (CGCCGC to GCCGCC) point 
401 mutation. The FHOD1 cDNA was inserted into pMSCV-puro EGFP-C4 vector with BamHI and

402 Notl restriction sites. The shRNA sequences for NC and FHOD1 were 5'-

403 caacaagatgaagagcaccaa-3' and 5'-gaacctctttcctaccatttc-3', respectively.

405 Cell culture, virus production, infection, and drug selection

406 NIH3T3 fibroblasts were maintained in Dulbecco's Modified Eagle Medium (DMEM; Corning Inc.)

407 containing 10 mM HEPES pH 7.4 and 10\% (v/v) bovine calf serum (GE Health Life Science).

408 Meanwhile, 293T cells were maintained in DMEM containing $10 \mathrm{mM} \mathrm{HEPES} \mathrm{pH} 7.4$ and 5\% (v/v)

409 bovine calf serum and 5\% (v/v) fetal bovine serum (Gemini Bio-Products). The 293T cells were

410 transfected with retroviral vectors and pantropic packaging plasmids. Medium containing the

411 produced virus was harvested $24 \mathrm{hr}$ after transfection, added to the NIH3T3 fibroblasts in the

412 presence of $2 \mu \mathrm{g} / \mathrm{ml}$ polybrene (EDM Millipore TR_1003) and incubated for one day. The

413 infected cells were selected with $300 \mu \mathrm{g} / \mathrm{ml}$ hygromycin B (EDM Millipore 400051) and $1.5 \mu \mathrm{g} / \mathrm{ml}$

414 puromycin (Sigma-Aldrich P8833) for one week. The cells were recovered from drug treatment

415 for one additional week before used for the experiments.

417 Immunofluorescence microscopy

418 For indirect immunofluorescence microscopy, cells were fixed with $4 \%$ paraformaldehyde in 419 phosphate-buffered saline (PBS) for $20 \mathrm{~min}$, then they were permeabilized and blocked with

420 PBS containing $0.1 \%$ Triton- $\mathrm{X}$ and $1 \%$ BSA for 30 min. The cells were labeled first with primary

421 antibodies and then fluorescently-labeled secondary antibodies (EMD Millipore AB16901) and

422 DAPI (Thermo Fisher Scientific D3571). Images were acquired with a 40× PlanApo objective

423 (NA 1.0) and DS-Qi2 (Nikon) on a Nikon Eclipse Ti microscope controlled by Nikon's NIS-

424 Elements software. 


\section{Western blotting}

427 Proteins were separated by SDS-PAGE then transferred onto a nitrocellulose blots, probed with 428 antibodies and detected either by chemiluminescence with Odyssey Fc (LI-COR Inc.) or infra429 red fluorescence with Odyssey CLx (LI-COR Inc.). The antibodies used were mouse 430 monoclonal GFP antibody (Santa Cruz, sc-9996), rabbit polyclonal FHOD1 antibody (Santa 431 Cruz, sc-99209, discontinued, rat Monoclonal tyrosinated-alpha-tubulin (YL-1/2) (European

432 Collection of Authenticated Cell Cultures, 92092402).

\section{LPA stimulation}

435 A day before serum-starvation, NIH3T3 fibroblasts were plated on acid-washed coverslips. The 436 next day, cells at about $40 \%$ confluency on coverslips were washed three times with DMEM and 437 then DMEM containing $10 \mathrm{mM}$ HEPES $\mathrm{pH} 7.4$ and $0.1 \%(\mathrm{v} / \mathrm{v})$ fatty acid free bovine serum 438 albumin (Sigma-Aldrich, A7906) was added. After two days serum-starvation, the cells were 439 stimulated with $10 \mu \mathrm{M}$ LPA (Avanti Polar Lipids, 857130P) and fixed after 2 hours.

\section{Cell analysis}

442 The position of centrosome relative to the axis between the nuclei and the leading edge was 443 analyzed from images of DAPI, tubulin and $\beta$-catenin/pericentrin antibody-labeled cells as

444 previously described ${ }^{37,38}$. Nuclear and centrosomal positions of NIH3T3 fibroblasts were 445 determined from images using Cell Plot software ${ }^{39}$. Statistical analysis of data on centrosome 446 reorientation was assessed by Chi-square test using GraphPad Software. Statistical evaluation

447 of the position of the nucleus and centrosome in NIH3T3 fibroblasts was by one-way ANOVA 448 followed by Tukey's multiple comparison test using SAS. All evaluated data were from at least $449 \mathrm{~N}=3$ experiments. 
bioRxiv preprint doi: https://doi.org/10.1101/2020.06.19.161299; this version posted June 20, 2020. The copyright holder for this preprint (which was not certified by peer review) is the author/funder, who has granted bioRxiv a license to display the preprint in perpetuity. It is made available under aCC-BY 4.0 International license. 
453 Table 1. Data collection and refinement statistics (molecular replacement)

454

Human Nes2G-SR11/12 $1425-1649$

FHOD1 $_{1-339}$
Human Nes1G-SR17/18 $1976-2200$

FHOD1 $_{1-339}$

\section{Data collection}

Space group

C 2

C 2

\section{Cell dimensions}
$a, b, c(\AA)$
$\alpha, \beta, \gamma\left(^{\circ}\right)$

Resolution $(\AA)$

$\mathrm{R}_{\text {pim }}$

$I / \sigma(I)$

$C C_{1 / 2}$

Completeness (\%)

Total reflections

Unique reflections

Redundancy

\section{Refinement}

Resolution $(\AA)$

No. reflections

$R_{\text {work }} / R_{\text {free }}$

No. atoms

Protein

Ligand/ion
$237.8,52.4,117.5$

$90.0,123.3,90.0$

$67.3-2.8(2.9-2.8)$

0.07 (1.3)

$21.6(1.9)$

0.54

$98.9(96.1)$

50981

8641

5.9

$67.3-2.8$

45282

$0.22 / 0.27$

8568

8536
$245.1,57.7,140.8$

$90.0,125.5,90.0$

99.0 - 7.0 (7.3 - 7.0)

$0.16(0.9)$

$6.1(0.8)$

0.50

$97.7(91.5)$

5293

2635

2.0

$99.7-7.0$

2634

$0.37 / 0.42$

6062

6062 
Water

\section{B-factors $\left(\AA^{2}\right)$}

Protein 77.5

400.5

Ligands/ion

112

Water

80.4

r.m.s. deviations

Bond lengths $(\AA)$

0.01

0.02

Bond angles $\left({ }^{\circ}\right)$

\section{Ramachandran}

analysis

Favored (\%)

Allowed (\%)

Outliers (\%)
96.3

3.3

0.4
96.4

3.5

0.1

*Values in parentheses are for highest-resolution shell.

\section{$458 \quad$ Figure Legend}

459 Figure 1: Structure of the FHOD1-N and Nes2G-SR11/12 complex.

460 a, Schematic diagram to show the boundaries of FHOD1-N, Nes2G-SR11/12, and Nes1G-

461 SR17/18 fragments in the context of the full-length protein. b, Overall crystal structure of

462 Nes2G-SR11/12 bound to FHOD1-N with interface residues, as part of the main interaction sites

463 A and B shown as sticks. Nes2G in blue, FHOD1 in orange. c, d, Close-up views of key 464 interaction sites within site A. C and D show the same perspective, with different, otherwise 465 overlapping residues, removed for clarity. H-bonds and charged interactions shown as black 466 dashed lines. c, emphasizes charged interactions, d, a critical hydrophobic interaction. e, Close- 
467 up view of site $B$ dominated by the $\mathrm{EPR}_{36-38}$ element of the SRBM of FHOD1. A water molecule

468 in red.

469

470

471 Figure 2: Sequence alignment and conservation analysis of FHOD1-N and Nes2G-SR11/12.

472 a, Sequence alignment for FHOD1-N and b, Nes2G-SR11/12 using a blue-to-white color

473 gradient to indicate high-to-low conservation. Secondary structure elements are indicated above

474 the sequence alignment. Interface residues of the complex interaction sites are indicated by

475 grey bars, representing the degree of burial upon binding. Other symbols denote salt bridges

476 (red triangles) and hydrogen-bonds (black discs).

479 Figure 3: Analysis of residues involved in FHOD1-N-Nes2G-SR11/12 complex formation.

480 a, Size exclusion chromatography (SEC) profile of purified FHOD1-N incubated with wildtype

481 Nes2G-SR11/12, or mutant variants. Only the wildtype stably binds. b, Complementary

482 experiment with Nes2G-SR11/12, and wildtype or mutant FHOD1-N fragments. Both

483 experiments were carried out on a Superdex S75 10/300 column. c, SDS-PAGE analysis of the

484 SEC elution fractions (black bars) in A and B. d, Binding activity of the two proteins with Biolayer

485 interferometry (BLI) where Nes2G-SR11/12 is immobilized as ligand tested against the indicated 486 analytes.

489 Figure 4: FHOD1 R136A R137A double mutant $(\mathrm{RR})$ fails to rescue centrosome orientation and 490 nuclear movement.

491 a, Western blots of lysates from NIH3T3 fibroblasts with or without FHOD1 shRNA (shFHOD1) 492 expression and expressing either EGFP or EGFP-tagged FHOD1 proteins. Antibodies used to 
493 probe the blots are indicated on the right. FHOD1 RR is FHOD1 with R136A R137A point

494 mutations. b, Images of LPA-stimulated wound-edge NIH3T3 fibroblasts expressing EGFP or 495 FHOD1 proteins after knockdown of FHOD1 (shFHOD1) and stained for the indicated proteins 496 and DAPI. NC is a negative control shRNA. White arrows, oriented centrosomes. Bar, $20 \mu \mathrm{m}$. c, 497 Quantification of centrosome and nuclear positions and centrosome orientation for the cells 498 treated as in $A$. Values are means \pm SEM; $n$, cells examined. Centrosome orientation (mean \% 499 of cells), is shown in the heat map below the histograms. ${ }^{* 1}$ and ${ }^{* 2}$ indicate $p<0.01$ compared to 500 the LPA-stimulated control to the rest of the samples for each category

Figure 5: Nes1G-SR17/18 is another FHOD1-binding spectrin repeat.

a, Sequence alignment of the two tandem SRs that have a matching sequence pattern indicative of FHOD1 binding. The search sequence is shown below the alignment. Conserved interface residues involved in site $A$ and site $B$ are labelled and the critical motif highlighted in

507 box $\mathbf{b}$, SEC profile of Nes1G-SR17/18 incubated with or without FHOD1-N, with SDS PAGE 508 analysis of the eluted fractions. c, BLI binding assay of Nes1G-SR17/18 and FHOD1-N. 509 Individual curves represent a 2-fold dilution series from a maximal concentration of $400 \mathrm{nM} \mathrm{d}$, 510 Setup as in b but using mutant Nes1G-SR17/18 D2176A D2180A instead of wildtype. Both 511 SEC experiments were performed on a Superdex S75 10/300 column. e, Binding assay of 512 wildtype and mutant FHOD1-N with Nes1G-SR17/18 measured by BLI.

515 Figure 6: SR18 of Nes1G is sufficient to bind FHOD1-N.

516 a, Crystal structure of FHOD1-N bound with Nes1G-SR17-18 at 7.0 A resolution with 2Fo-Fc 517 map contoured at 1.2 sigma. SR17 was not modeled because of insufficient electron density. 518 Nes2G-SR11/12 (blue) overlaid for comparison. b, SEC experiment of Nes1G-SR18 with or 
519 without FHOD1-N, accompanied by SDS-PAGE analysis of the eluted fractions. c, Binding of

520 Nes1G SR18 with FHOD1-N measured by BLI.

521

522 Figure 7: SR binding to FHOD1 does not sterically compete with DAD autoregulatory binding.

523 a, The Nes2G-SR11/12-FHOD1-N complex overlaid with the DAD helix (cyan). The DAD helix

524 was positioned based on an alignment with the mDia-FH3 domain bound to its DAD helix (PDB

525 code 2F31). FHOD1-V228, critical for DAD-binding in deep-orange. b, Analytical SEC of MBP-

526 DAD with Nes2G-SR11/12 and FHOD1-N complex (left panel) or FHOD1-N alone (right panel)

527 in the presence of 3C protease. A Superdex S75 10/300 GL column was used in all the SEC

528 experiments. Uncleaved MBP-DAD $\left(^{*}\right)$ was run as a control.

530 Figure 8: Modulation of the FH3 binding activity by its N-terminally paired domain

531 a, Comparison between GBD-FH3 of mDia1 bound to the small GTPase Cdc42 and b, SRBM-

532 FH3 of FHOD1 bound to Nes2G-SR11/12. Structures are aligned using the FH3 domain.

533 Binding surfaces outlined. Paired SRBM- or GBD-FH3 domains shown as surfaces, gradient-

534 colored according to conservation as indicated. DAD helix position modeled (cyan). SR and

535 small GTPase bind in mutually exclusive positions. Surfaces are specifically conserved to

536 recognize either SR or small GTPases, defining a difference between the two classes of formins.

538 Figure 9: Model for connecting actin bundles with the nucleus.

539 A cartoon depiction of the Nes2G-FHOD1 structure in the context of TAN lines. FHOD1 binds to

540 the barbed end of long actin polymer. a, Its association with Nes2G can either enforce binding

541 of LINC to a single actin polymer or $\mathbf{b}$, could play a part in the bundling of actin cables. 


\section{Acknowledgements}

Research was supported by the US NIH under grant number R01-AR065484 (T.U.S.)

547 and T32GM007287 (V.C.). The X-ray crystallography work was conducted at the APS NE-CAT

548 beamlines, which are supported by NIH award GM103403. Use of the APS is supported by the

549 US Department of Energy, Office of Basic Energy Sciences, under contract no. DE-AC02-

$550 \quad 06 \mathrm{CH} 11357$.

551

\section{Author Contributions}

553 S.M.L. and T.U.S. designed the study. S.M.L. and V.E.C. performed the experiments.

554 G.G.G. and S.A. contributed Figure 4. S.M. L. and T.U.S. interpreted the results and wrote the 555 manuscript with input from G.G.G., S.A., and V.E.C..

\section{Competing Interests}

557 The authors declare no competing financial interests.

\section{References}

561 1. Gundersen, G. G. \& Worman, H. J. Nuclear Positioning. Cell 152, 1376-1389 (2013).

562 2. Crisp, M. et al. Coupling of the nucleus and cytoplasm: role of the LINC complex. J. Cell Biol.

$563172,41-53(2006)$.

564 3. Starr, D. A. \& Fridolfsson, H. N. Interactions between nuclei and the cytoskeleton are

565 mediated by SUN-KASH nuclear-envelope bridges. Ann. Rev. Cell Dev. Bio. 26, 421-444

566 (2010). 
567 4. Sosa, B. A., Rothballer, A., Kutay, U. \& Schwartz, T. U. LINC Complexes Form by Binding of

568 Three KASH Peptides to Domain Interfaces of Trimeric SUN Proteins. Cell 149, 1035-1047

569 (2012).

570 5. Horn, H. F. LINC complex proteins in development and disease. Curr Top Dev Biol 109, 287-

$571321(2014)$

572 6. Calvi, A. \& Burke, B. LINC Complexes and Their Role in Human Disease. eLS (2015).

573 7. Janin, A., Bauer, D., Ratti, F., Millat, G. \& Méjat, A. Nuclear envelopathies: a complex LINC

574 between nuclear envelope and pathology. J. Rare Dis. 12, 147 (2017).

575 8. Luxton, G. W. G., Gomes, E. R., Folker, E. S., Vintinner, E. \& Gundersen, G. G. Linear Arrays

576 of Nuclear Envelope Proteins Harness Retrograde Actin Flow for Nuclear Movement. Science

$577329,956-959(2010)$.

578 9. Kutscheidt, S. et al. FHOD1 interaction with nesprin-2G mediates TAN line formation and

579 nuclear movement. Nat. Cell Biol. 16, 708-715 (2014).

580 10. Zhang, Q. et al. Nesprins: a novel family of spectrin-repeat-containing proteins that localize

581 to the nuclear membrane in multiple tissues. J. Cell Sci. 114, 4485-4498 (2001).

582 11. Rajgor, D. \& Shanahan, C. M. Nesprins: from the nuclear envelope and beyond. Expert. Rev.

583 Mol. Med. 15, e5 (2013).

584 12. Pruyne, D. Probing the origins of metazoan formin diversity: Evidence for evolutionary

585 relationships between metazoan and non-metazoan formin subtypes. PLOS One 12, e0186081

586 (2017).

587 13. Breitsprecher, D. \& Goode, B. L. Formins at a glance. J. Cell Sci.126, 1-7 (2013). 
588 14. Rivero, F. et al. A comparative sequence analysis reveals a common GBD/FH3-FH1-FH2-

589 DAD architecture in formins from Dictyostelium, fungi and metazoa. BMC Genomics 6, 28

590 (2005).

591 15. Higgs, H. N. Formin proteins: a domain-based approach. Trends Biochem. Sci. 30, 342-353

592 (2005).

593 16. Bechtold, M., Schultz, J. \& Bogdan, S. FHOD proteins in actin dynamics--a formin' class of

594 its own. Small GTPases 5, 11 (2014).

595 17. Higgs, H. N. \& Peterson, K. J. Phylogenetic Analysis of the Formin Homology 2 Domain.

596 MBoC 16, 1-13 (2004).

597 18. Lammers, M., Meyer, S., Kühlmann, D. \& Wittinghofer, A. Specificity of Interactions between

$598 \mathrm{mDia}$ Isoforms and Rho Proteins. J. Biol. Chem. 283, 35236-35246 (2008).

599 19. Kühn, S. et al. The structure of FMNL2-Cdc42 yields insights into the mechanism of

600 lamellipodia and filopodia formation. Nat. Commun. 6, 7088 (2015).

601 20. Schulte, A. et al. The human formin FHOD1 contains a bipartite structure of FH3 and

602 GTPase-binding domains required for activation. Structure 16, 1313-1323 (2008).

603 21. Kutscheidt, S. et al. FHOD1 interaction with nesprin-2G mediates TAN line formation and

604 nuclear movement. Nat. Cell Biol. 16, 708-715 (2014).

605 22. Antoku, S., Zhu, R., Kutscheidt, S., Fackler, O. T. \& Gundersen, G. G. Reinforcing the LINC

606 complex connection to actin filaments: the role of FHOD1 in TAN line formation and nuclear

607 movement. Cell Cycle 14, 2200-2205 (2015). 
609 Positioning Alternations in Cardiac Laminopathy. Dev. Cell 51, 602-616.e12 (2019).

610 24. Takeya, R., Taniguchi, K., Narumiya, S. \& Sumimoto, H. The mammalian formin FHOD1 is

611 activated through phosphorylation by ROCK and mediates thrombin-induced stress fibre

612 formation in endothelial cells. EMBO J. 27, 618-628 (2008).

613 25. Otomo, T., Tomchick, D. R., Otomo, C., Machius, M. \& Rosen, M. K. Crystal structure of the 614 Formin mDia1 in autoinhibited conformation. PLOS One 5, e12896 (2010).

615 26. Antoku, S., Zhu, R., Kutscheidt, S., Fackler, O. T. \& Gundersen, G. G. Reinforcing the LINC 616 complex connection to actin filaments: the role of FHOD1 in TAN line formation and nuclear 617 movement. Cell cycle 14, 2200-2205 (2015).

618 27. Schönichen, A. et al. FHOD1 is a combined actin filament capping and bundling factor that 619 selectively associates with actin arcs and stress fibers. J. Cell Sci. 126, 1891-1901 (2013).

620 28. Ipsaro, J. J. \& Mondragón, A. Structural basis for spectrin recognition by ankyrin. Blood 115, 621 4093-4101 (2010).

622 29. Aravind, L., Anantharaman, V., Balaji, S., Babu, M. M. \& Iyer, L. M. The many faces of the 623 helix-turn-helix domain: Transcription regulation and beyond. FEMS Microbiol. Rev. 29, 231$624262(2005)$

625 30. Smith, T. F. Diversity of WD-Repeat proteins. Subcell. Biochem. (2008).

626 31. Pruyne, D. Probing the origins of metazoan formin diversity: Evidence for evolutionary

627 relationships between metazoan and non-metazoan formin subtypes. PLOS One 12, e0186081 628 (2017). 
630 Ray Diffraction Data Collected in Oscillation Mode. Methods. Enz. 276 307-326 (1997).

631 33. Liebschner, D. et al. Macromolecular structure determination using X-rays, neutrons and 632 electrons: recent developments in Phenix. Acta Cryst. D 75, 861-877 (2019).

633 34. Schulte, A. et al. The human formin FHOD1 contains a bipartite structure of FH3 and

634 GTPase-binding domains required for activation. Structure 16, 1313-1323 (2008).

635 35. Emsley, P., Lohkamp, B., Scott, W. G. \& Cowtan, K. Features and development of Coot. 636 Acta Cryst. D 66, 486-501 (2010).

637 36. Brown, P. H. \& Schuck, P. Macromolecular Size-and-Shape Distributions by Sedimentation

638 Velocity Analytical Ultracentrifugation. Biophys. J. 90, 4651-4661 (2006).

639 37. Gomes, E. R., Jani, S. \& Gundersen, G. G. Nuclear Movement Regulated by Cdc42, MRCK, 640 Myosin, and Actin Flow Establishes MTOC Polarization in Migrating Cells. Cell 121, 451-463 641 (2005).

642 38. Palazzo, A. F., Cook, T. A., Alberts, A. S. \& Gundersen, G. G. mDia mediates Rho-regulated 643 formation and orientation of stable microtubules. Nat. Cell Biol. 3, 723-729 (2001).

644 39. Chang, W., Antoku, S. \& Gundersen, G. G. Wound-Healing Assays to Study Mechanisms of 645 Nuclear Movement in Fibroblasts and Myoblasts. Methods Mol. Biol. v1411, 20-30 (2016). 


\section{Figure 1}

bioRxiv preprint doi: https://doi.org/10.1101/2020.06.19.161299; this version posted June 20, 2020. The copyright holder for this preprint (which was not certified by peer review) is the eltherffynder, who has granted bioRxiv a license to display the preprint in perpetuity. It is made a

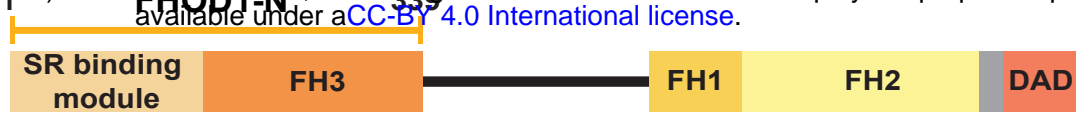

Nes2G SR11-12

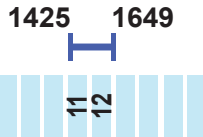

Calponin

Homology

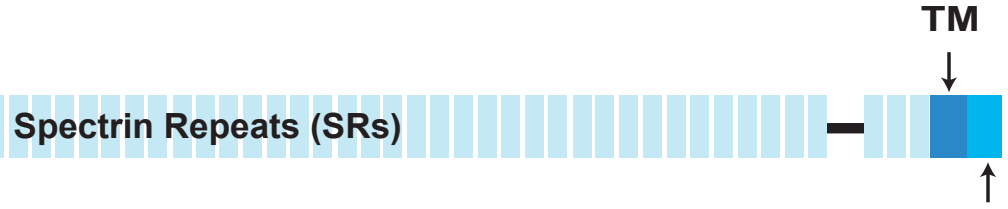

KASH element

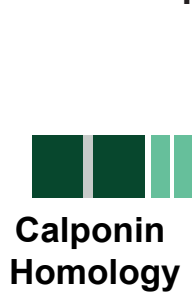

Nes1G SR17-18

$1976 \quad 2220$

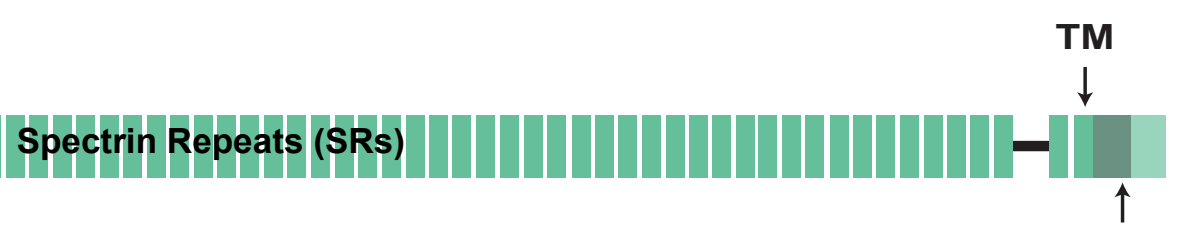

\section{Homology}

KASH element

b

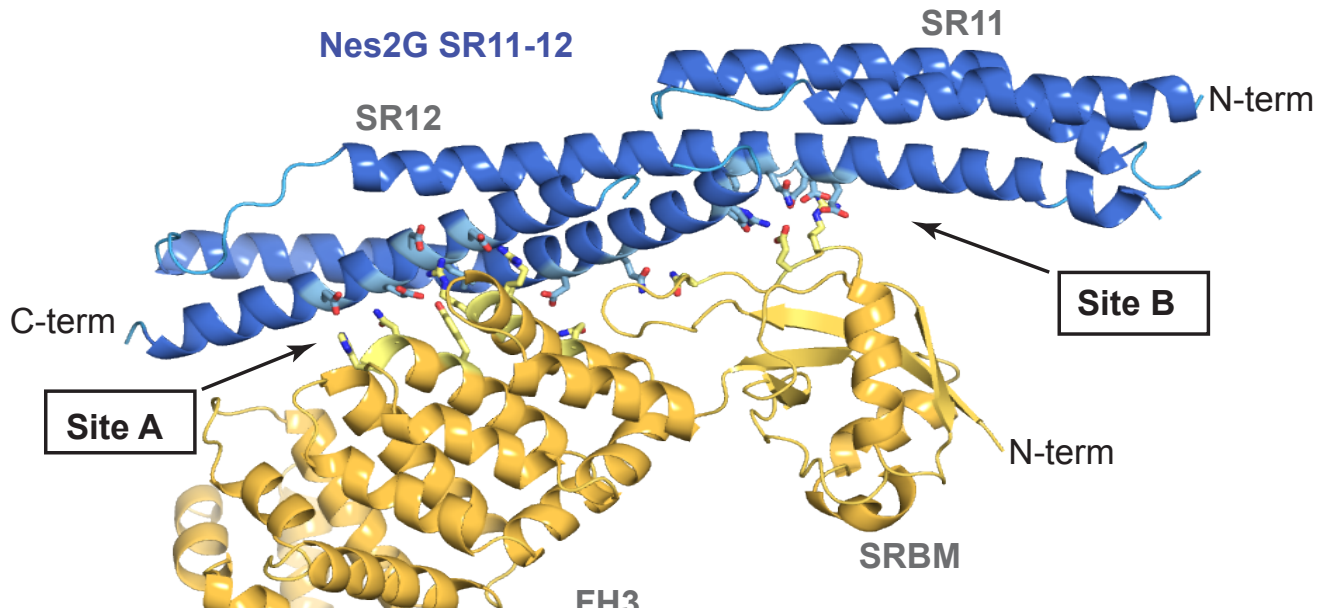

FHOD1-N

Site A

Site B
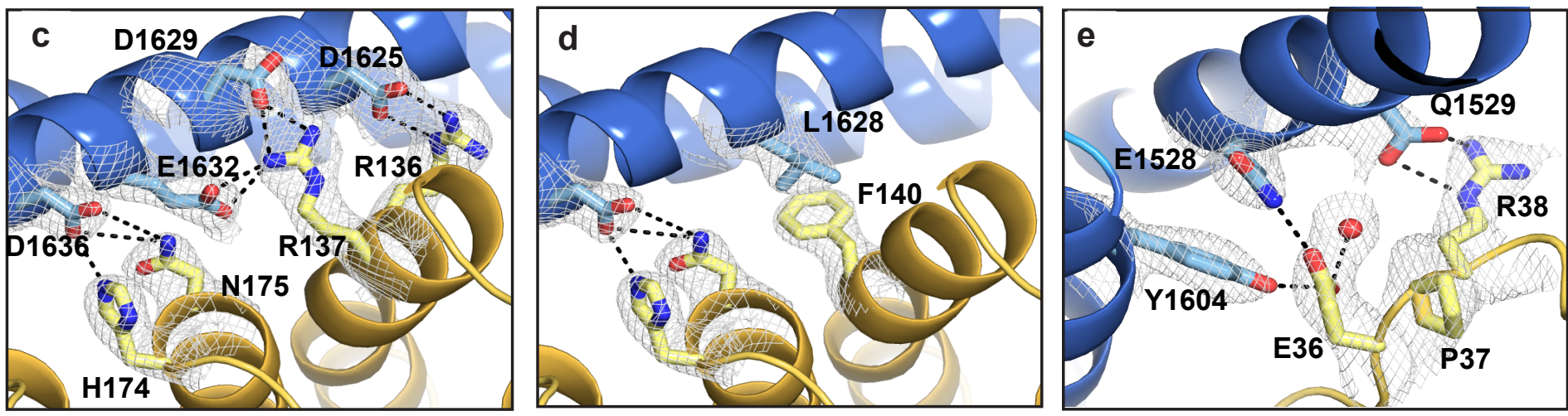


\section{Figure 2}

bioRxiv preprint doi: https://doi.org/10.1101/2020.06.19.161299; this version posted June 20, 2020. The copyright holder for this preprint a (which was not certified by peer review) is the author/funder, who has granted bioRxiv a license to display theitige $\mathbb{B}_{\text {print }}$ in perpetuity. It is made

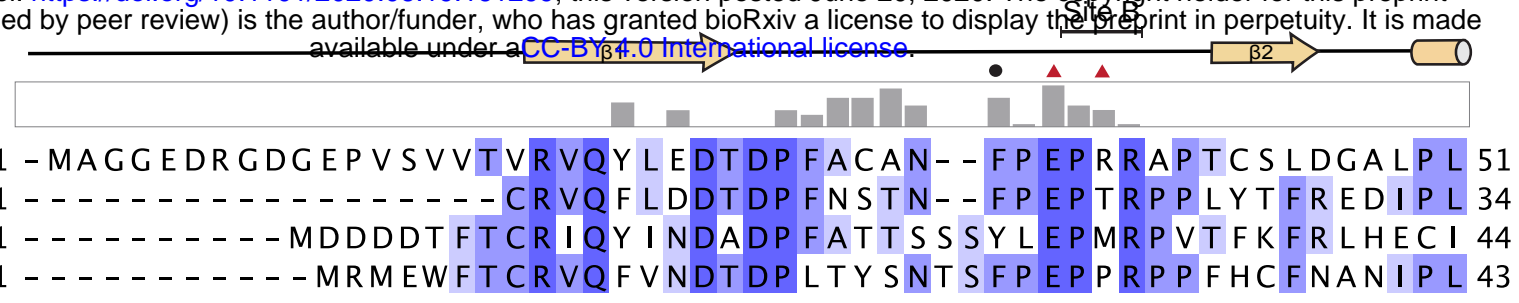

H. sapiens FHOD1

T. rubripes FHOD1

C. elegans FHOD1

D. pulex FHOD

H. sapiens FHOD1

T. rubripes FHOD1

C. elegans FHOD1

D. pulex FHOD

H. sapiens FHOD1

T. rubripes FHOD1

C. elegans FHOD1

D. pulex FHOD

H. sapiens FHOD1

T. rubripes FHOD1

C. elegans FHOD1

D. pulex FHOD

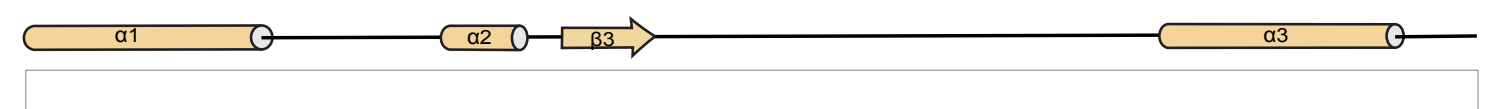

52 GAQ I PAVHRLLGAPLKLEDCALQVSP S - - - - - - - YYLDTELSLEEQREMLEG 97 35 I NQ I AGVHR L LKAPHRPDDCALQLSHN- - G - - - SYLDLESTLAEQGDELEG 80 45 S DQ LQDV I RT LR AP HKAGDS S LQVYRGLEGGGGE L HTY LDNDMTLTDQQE E L I 98 44 VNQLPAVHR L LGAPHQLGDAT FQVYKDGDYG- - - - NY LDVEATLNEQSEELEG 92

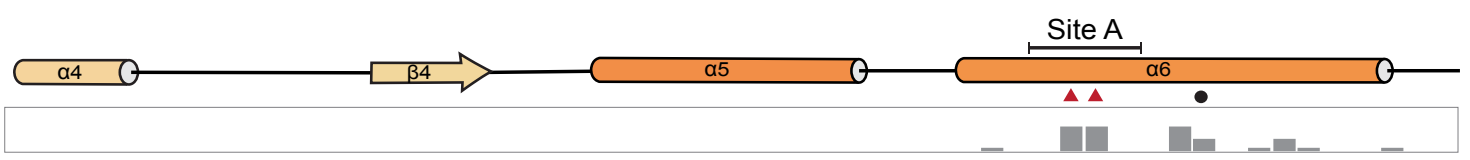

98 FYEE - I SKGRKPTL I LRTQLSVRVNA I LEKLYS S SGPELRR SLFSLKQ I FQEDK 150 81 FQEEGLRRGKKHS I VLRTQLS IRVHAC I EK LYNSTGRELRRALFSLKQ I FQDDK 134 99 LKAD - - - TRR C S LVLRTQT S LRVKT I I DK L LNCSGR DQRR A LF S LKQ I FQDDQ 148 93 FLEN- - - - RKNS I VLRTQLSVR VNGIMDKLLHSEGKELRRALFSLKQIFQEDK 141

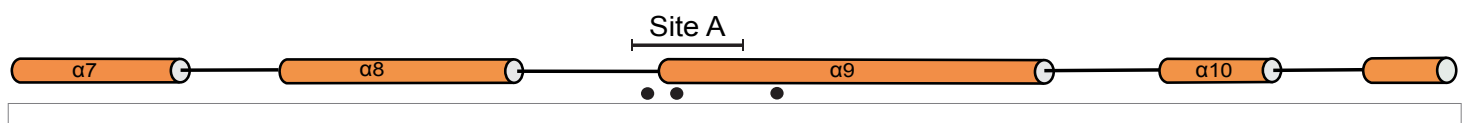

151 DLVPEFVHSEGLSCLIRVGAAADHNYQSY I LRALGQLMLFVDGMLGVVAHSDTI 204 135 D LVHEFVVAEGLTCL I KVGAEADQNYQNY I LRA LGQ I M LYVDGMNGL I SHNETV 188 149 D LVHE FVQNQG LDCM I R LGRTADQNHQNY I LRA LGQ LMLYVDGMNG I A ANGT I 202 142 DLVHEFVQNDG LACLI R VGHTADQNFQNY I LRA LGQVMLYVDGMNGVMEHNPTV 195

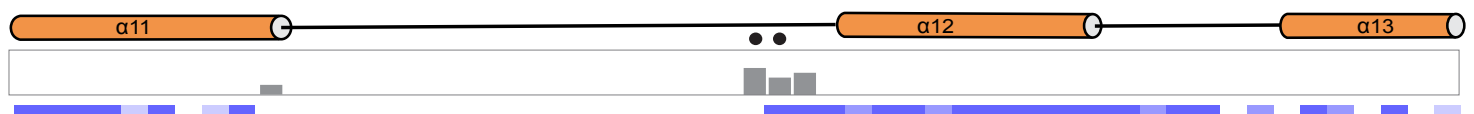

205 QWLYTLCASL_. - . - . - . . . . - - SR LVVKTALKLLLVFVEYSENNAP LF I 241

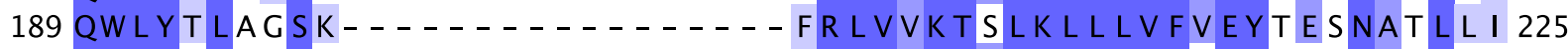
203 QW LYE LLDSP LY I DEERKEMSPFR LEWFR LVVKTALKLLLVF I EYNDNNAL LVL 256 196 QWLYSL I ASK - . - . . . . . . - YR LVAKTALKLLLVFVEYVESNCQLLV 232

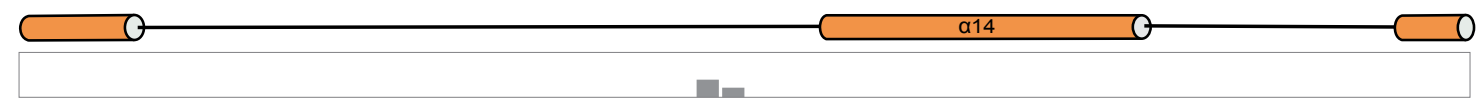

H. sapiens FHOD1 242 RAVNSVASTTGAP PWANLVS I LEEKNGADP E LVYTVTL I NKTLAALPDQDSFY 295

T. rubripes FHOD1 226 K A V DV VDGKR GQK LWS N I ME I LDEKDGVDTE L LVYGMTL I NKTLAGLLDQDSYY 279

C. elegans FHOD1 257 TA I QTVDK S KGQADW S LMK VLTEKDSPDAETLVYGMTVVNKALHG I P DR DTYY 310

D. pulex FHOD 233 KA I ETVDSGQDSKPWS L LR L LQERDS SDSELLVYAVTLINKTLHGLPDQDSYY 286

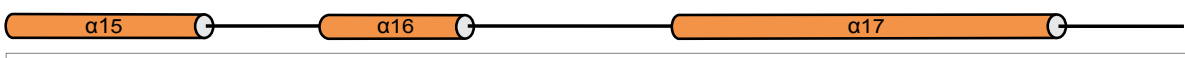

H. sapiens FHOD1 296 DVTDA LQQGMEA LVQRHLGTAGTDVDLRTQLVLYENALKLEDC

T. rubripes FHOD1 280 DMVDG LEEQG I EV LGQRHLSRKGTDLDLVEQFN I Y EMT LRHEDG

C. elegans FHOD1 311 DAVDT LDT LGMEDA I K SM- - SR SNNKELEEQCR LYERELKEED-

D. pulex FHOD 287 DQ I ENLEA LGMQQ I VTR F VSKP EGDADL I QQ LE I Y EHQLKQEDG

\begin{tabular}{|l|l|}
\hline Legend \\
SRBM & \\
FH3 & \\
Buried interface & \\
Hydrogen bond & \\
Salt bridge & \\
\hline
\end{tabular}


bioRxiv preprint doi: https://doi.org/10.1101/2020.06.19.161299; this version posted June 20, 2020. The copyright holder for this preprint (whligh was not certified by peer review) is the author/funder, who has granted bioRxiv a license to display the preprint in perpetuity. It is made avaliaboser under aCe-BY 4.0 international license

H. sapiens Nes2 O. anatinus Nes2 G. gallus Nes2

D. rerio Nes2a

H. sapiens Nes2 O. anatinus Nes2 G. gallus Nes2 D. rerio Nes2a

H. sapiens Nes2 0 . anatinus Nes2 G. gallus Nes2 D. rerio Nes2a

H. sapiens Nes2 O. anatinus Nes2 G. gallus Nes2 D. rerio Nes2a 1515 2054
ENK L LEAC I FKNNE L LKN I QDVQSQ I SK I G LKDPTVPAVKHRKK S I 1471 RRQLLEAFLAKNNELLKN I QDVQDQ I NT I GLKDST I PAVSHR I K S LT 1478 GNDLYK I F STRNEELLKN I QDLHDR I NK I GLKDPTAPA I QQR VK S LM 1420 EKKEERAFGRKRMGL LVTLREVLAALERHVLKEPTLPALQHR LR FLT 1971

\section{SR11 a2}

1472

1479

1421

1972

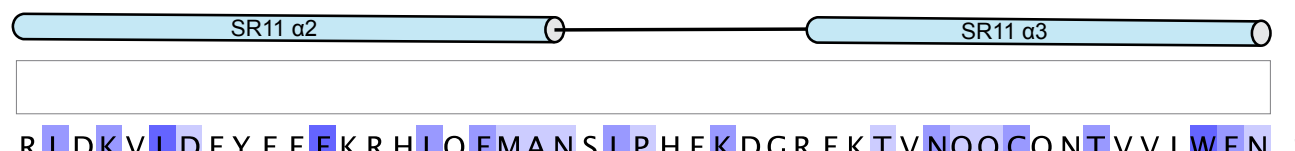

R LDKVLDEYEEEKRHLQEMANS LPHFKDGREKTVNQQCQNTVVLWEN 1518 ELEKKLNDFGRE I EY LWEMAEA LPQLKTDKGEMPNQLCRATECFWDN 1525 ELEK E LDC S A V EMK SMR E I T NK L LQMK E EKA E E SNEQCR VTER SWED 1467 DMESKLHALR SE I DDLRD - - - - - - - - ANT SDTNLSELQTQWET 2006 Site B

$\overbrace{\Delta \bullet \Delta}^{\text {Site B }}$

1519 TKALVTECLEQCGR V LELLKQYQNFK S I LTTL I QKEES I S LQASYM 1526 VK S S V VECLEQCER I MELLKQYQSCK S VLTTL I QKKES I V SQQA SYM 1468 TKL LLAECQEQCARA LE L LKQYQ SCK S S LTS I I QKQE I VL SQQNSYM 2007 AHR S VTESREQCA S LTELLKK FQ S CR NNLGGT LQRAEQT I GDQA SYM

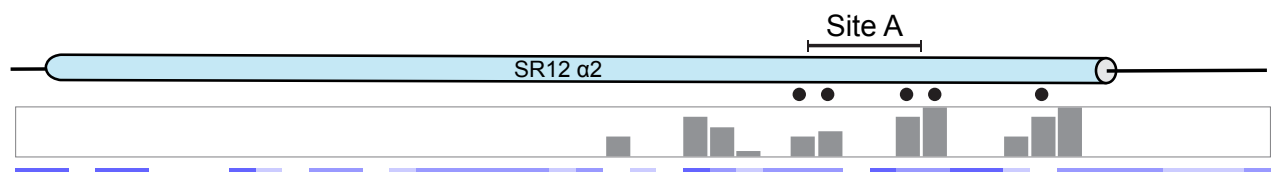

GKENLKKR I AE I E I VKEEFNEHLEVVDK I NQVCKNLQFYLNKMKTFE GKENLQRR I AT I EMVREEFNEHSQDVDR I NO I CKNLOYQLNKMKTYE 1619 GKDNLNRL I TK I EEAKEEFNDHAEDVDK I NQ I CKNLQFQLNKMR SFE 1561 GKDN LQLLI SKVI S I K SDLSGLGDGVEEFR SVCRQLQS LVRR V LDCT 2100

Site A

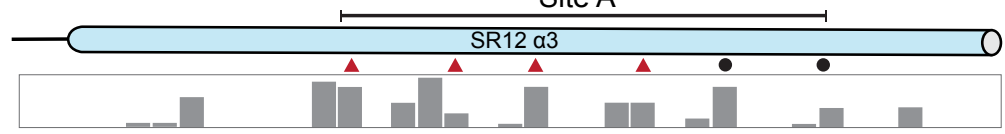

H. sapiens Nes2 1613 EP P F EK EAN I I VDRWLD I NE K T EDYYENLGRA LA LWD

O. anatinus Nes2 1620 EP P F EK EAN I I VDRW L DVNEK/T ENYYEN LGRA LA LWE

G. gallus Nes2 1562 EP P F ENEAN I I VDRWLD I NEKTT ENYCDN L GRAQA LWD

D. rerio Nes2a 2101 DAP F E S EADT LMDRW LDVTEKTDCY LDN LQAG F LWE

\begin{tabular}{l}
\hline Legend \\
SR \\
Overlapped region \\
Buried interface \\
Hydrogen bond \\
Salt bridge
\end{tabular}




\section{Figure 3}

bioRxiv preprint doi: https://doi.org/10.1101/2020.06.19.161299; this version posted June 20, 2020. The copyright holder for this preprint (which was not certified by peer review) is the author/funder, who has granted bioRxiv a license to display the preprint in perpetuity. It is made available under aCC-BY 4.0 International license.

a

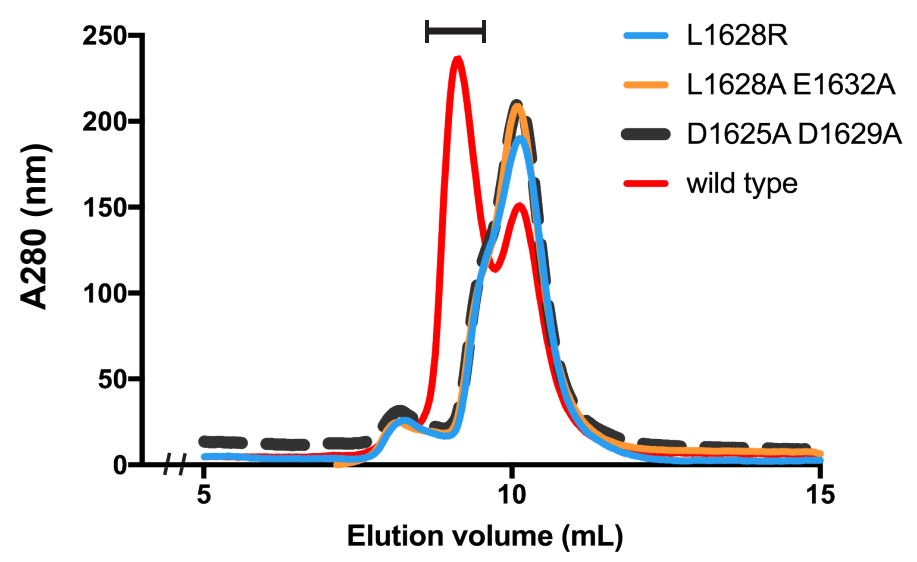

C
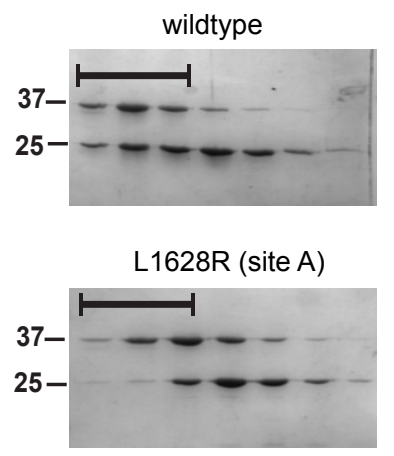

L1628A E1632A (site A)

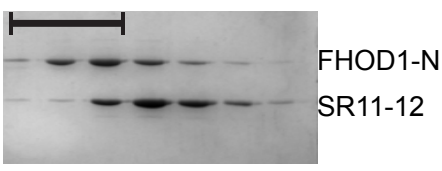

FHOD1-N mutants

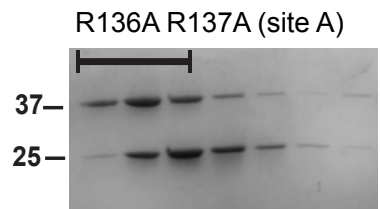

E36A P37G R38A (site B)

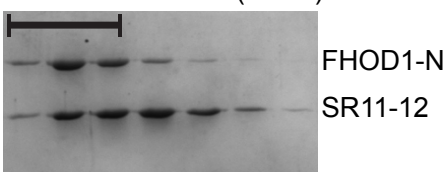

b

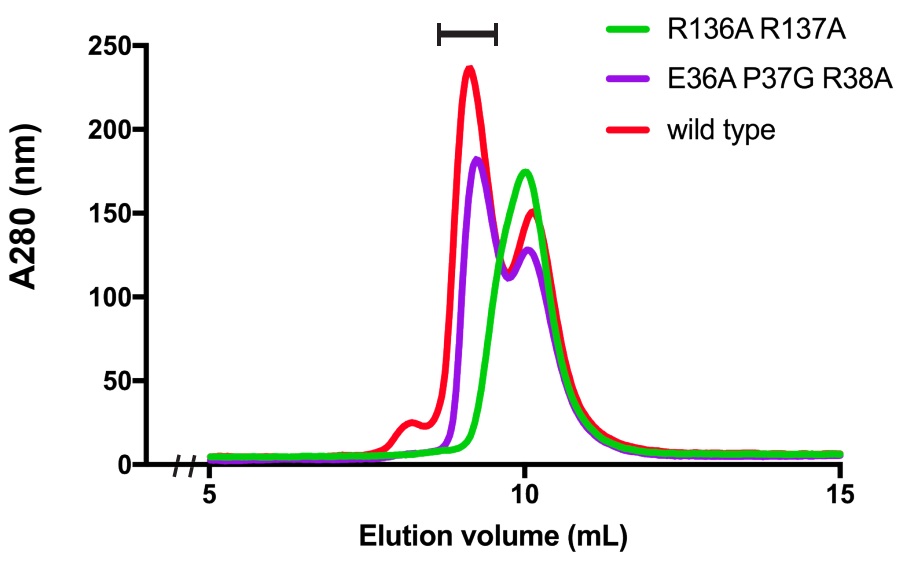

d
Binding assay of Nesprin2G SR11-12 with wild type and mutant FHOD1-N

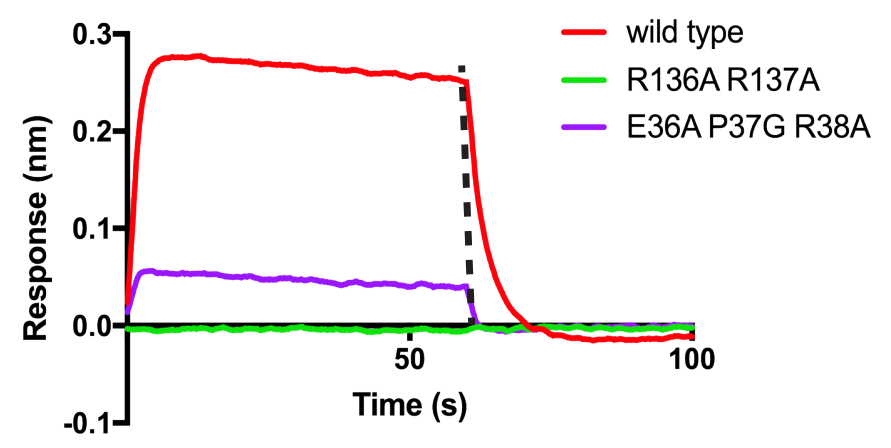


Figure 4

bioRxiv preprint doi: https://doi.org/10.1101/2020.06.19.161299; this version posted June 20, 2020. The copyright holder for this preprint (which was not certified by peer review) is the author/funder, who has granted bioRxiv a license to display the prepriatiamerpetuity thti $\$$ made

a

available under aCC-BY 4.0 International licens@GFP
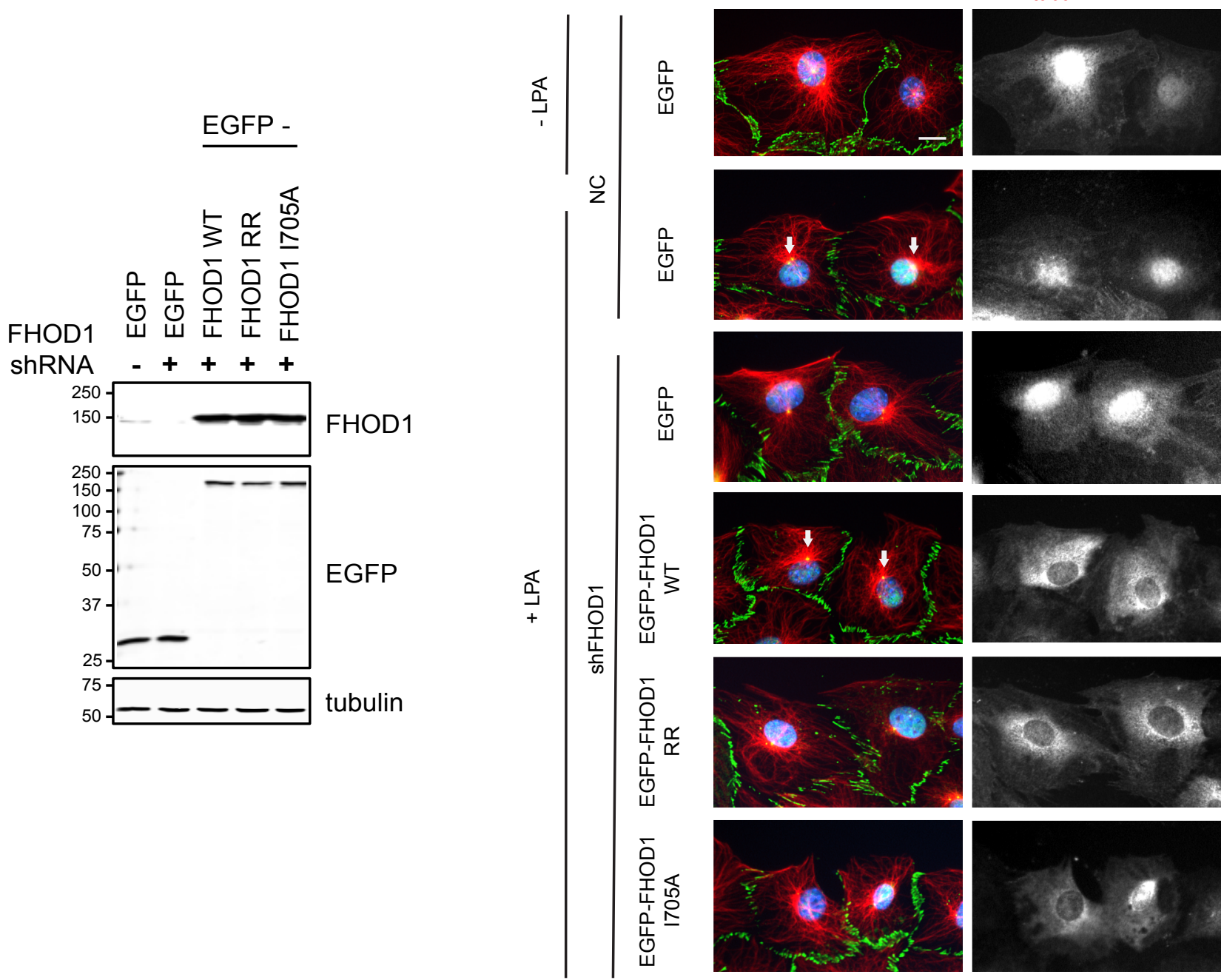

tubulin/DNA

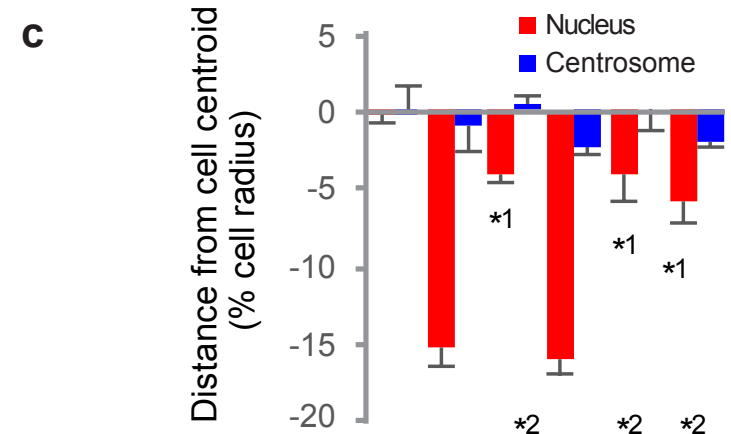

\begin{tabular}{lllllllll|}
\cline { 3 - 6 } Centrosome orientation & 34 & 62 & 33 & 58 & 35 & 35 &
\end{tabular}

(\% cells)

n 137130150134130119

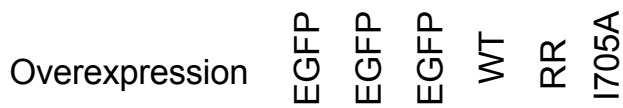

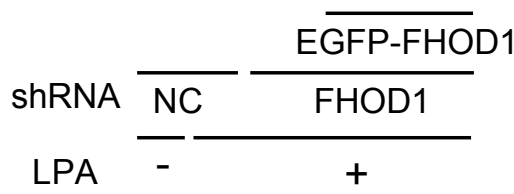




\section{Figure 5}

bioRxiv preprint doi: https://doi.org/10.1101/2020.06.19.161299; this version posted June 20, 2020. The copyright holder for this preprint (which was not certified by peer review) is the author/funder, who has granted bioRxiv a license to display the preprint in perpetuity. It is made available under aCC-BY 4.0 International license.

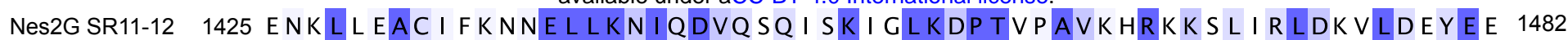

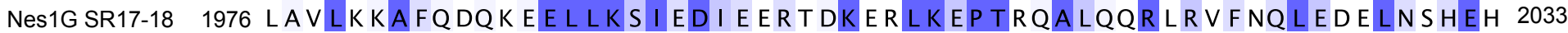

Site B

Nes2G SR11-12 1483 EKRHLQEMANSLPHFKDGREKTVNQQCQNTVVLWENTKALVTECLEQCGRVLELLKQY 1540 Nes1G SR17-18 2034 E LCWLKDKAKQ I AQKDVAFAP EVDRE I NR L EVTWDDT KR L I HENQGQCCGL I DLMREY 2091

Site A

Nes2G SR11-12 1541 QNFK S I LTTL I QKEESVI S LQA SYMGKENLKKR I AE I E I VKEEFNEHLEVVDK I NQVC 1598 Nes1G SR17-18 2092 QNLK SAVSK VLENAS S V IVTRTT I KDQEDLKWAF SKHETAKNKMNYKQKDLDNFT SKG 2149 Nes2G SR11-12 1599 KNLQFYLNKMKTFEEPPFEKEAN I I VDRWLDINEKTEDYYENLGRALA-WD Nes1G SR17-18 2150 KHLL S ELKK I HS S DF S LVKTDMESTVDKWLDVSEKLEENMDR LR V S L I WD

DxWLD[IVLA]XE

b

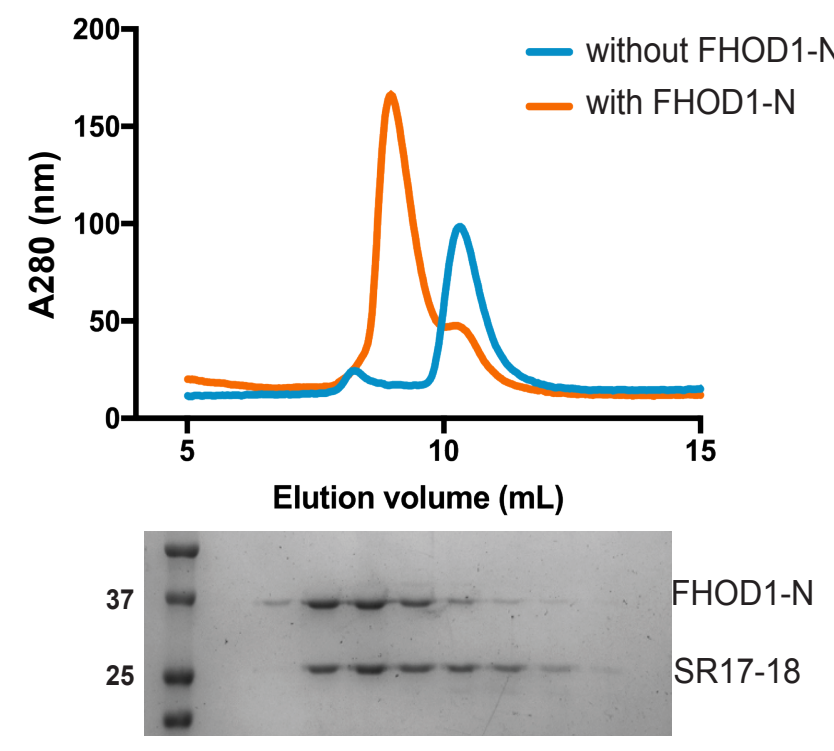

d

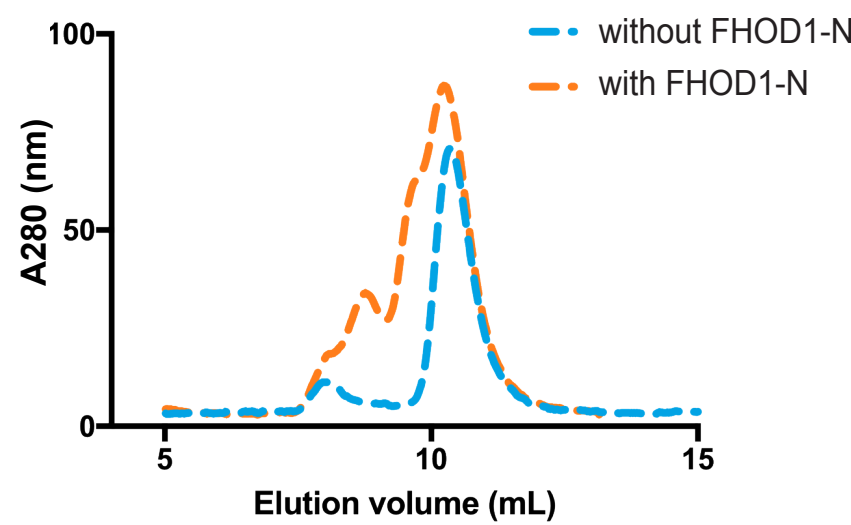

C

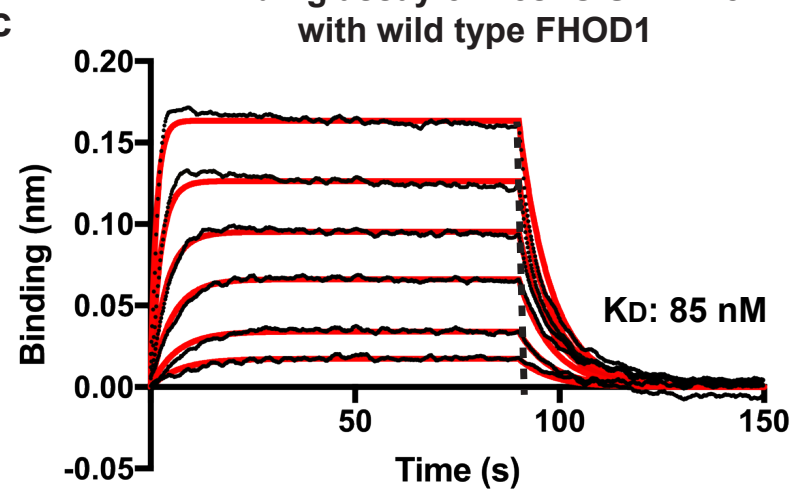

e Binding activity of Nes1G SR17-18 with wild type and mutant FHOD1

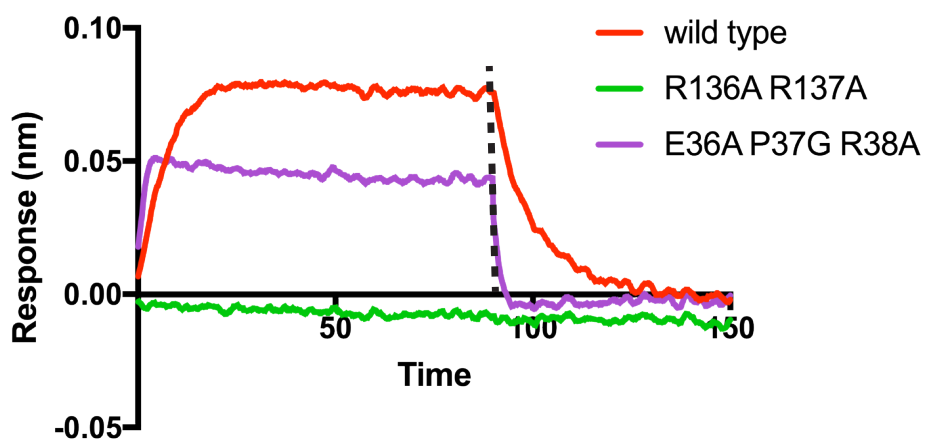

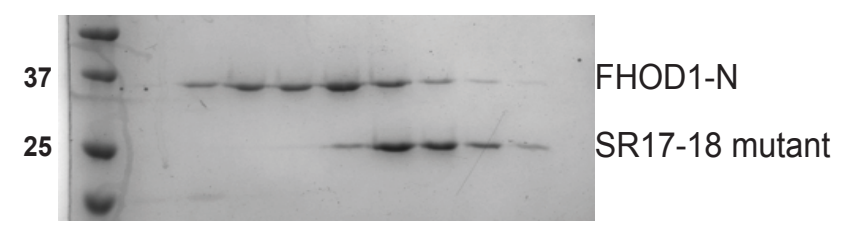


bioRxiv preprint doi: https://doi.org/10.1101/2020.06.19.161299; this version posted June 20, 2020. The copyright holder for this preprint (which was not certified by peer review) is the author/funder, who has granted bioRxiv a license to display the preprint in perpetuity. It is made available under aCC-BY 4.0 International license.

a
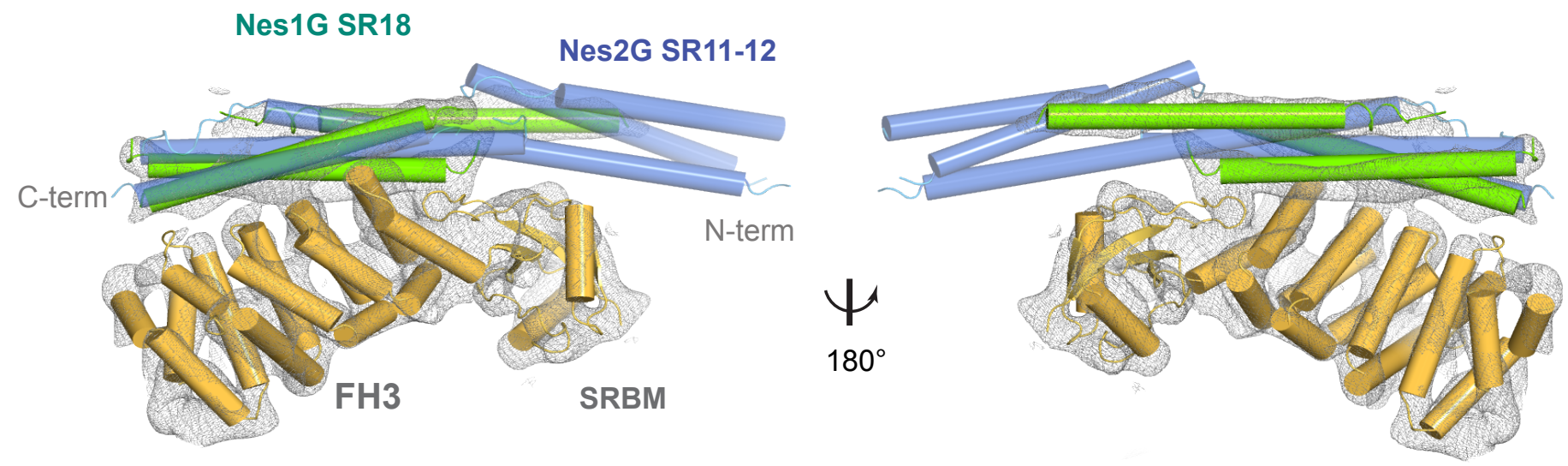

FHOD1-N

b

C
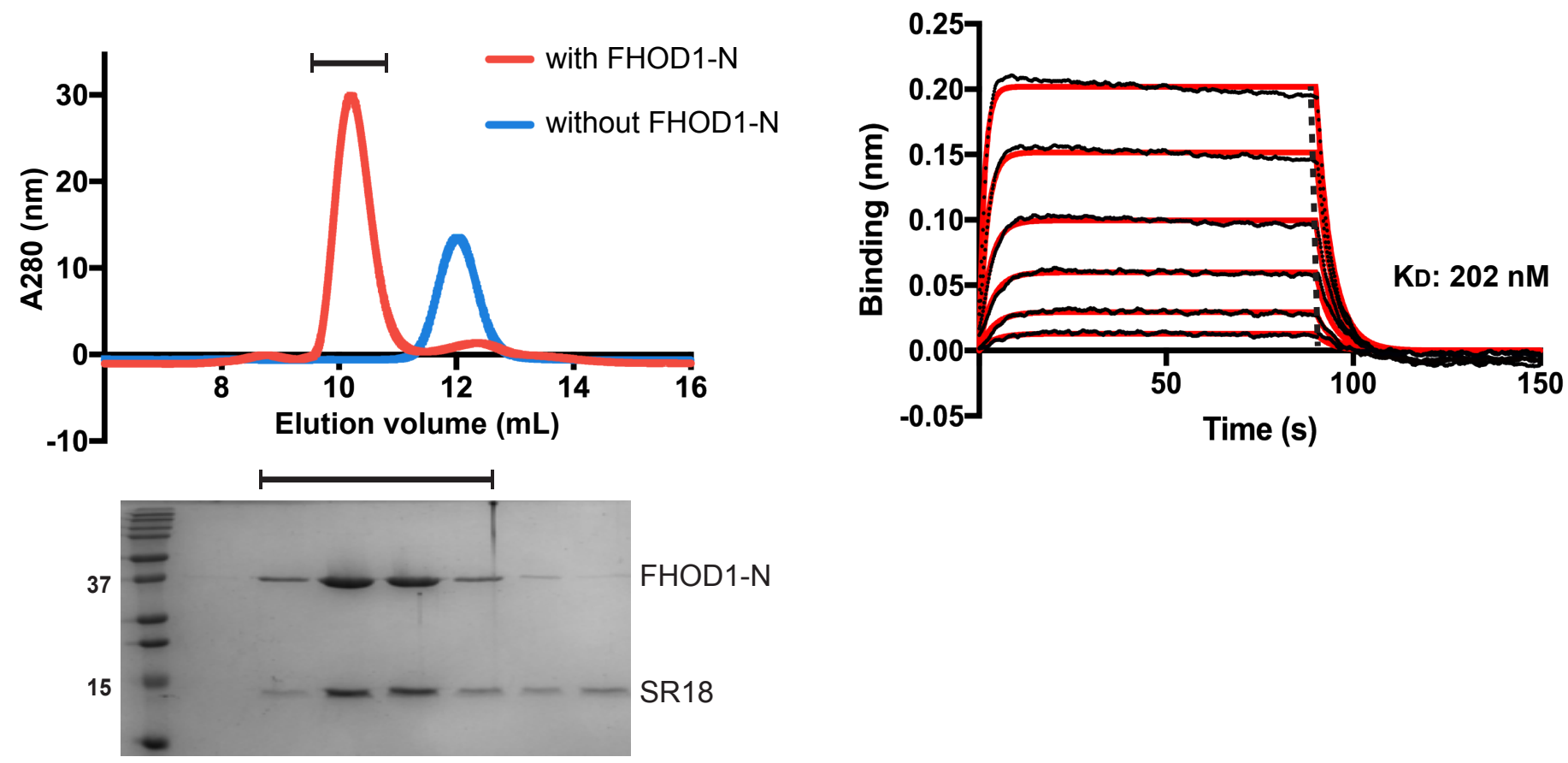
Figure 7

bioRxiv preprint doi: https://doi.org/10.1101/2020.06.19.16 299; this version posted June 20, 2020. The copyright holder for this preprint (which was not certified by peer review) is the author/funder, who has granted bioRxiv a license to display the preprint in perpetuity. It is made available under aCC-BY 4.0 International license.

a

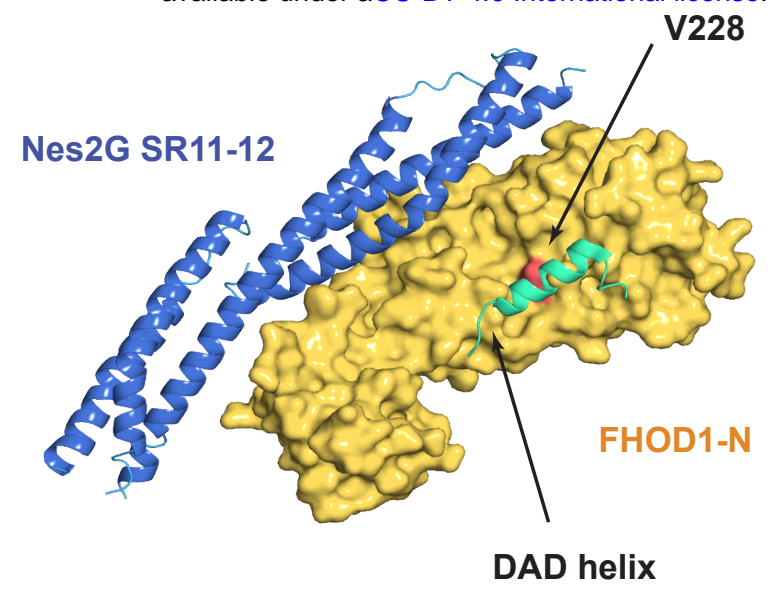

MBP-DAD

MBP

3C-Pre DAD 53.3 kDa

b
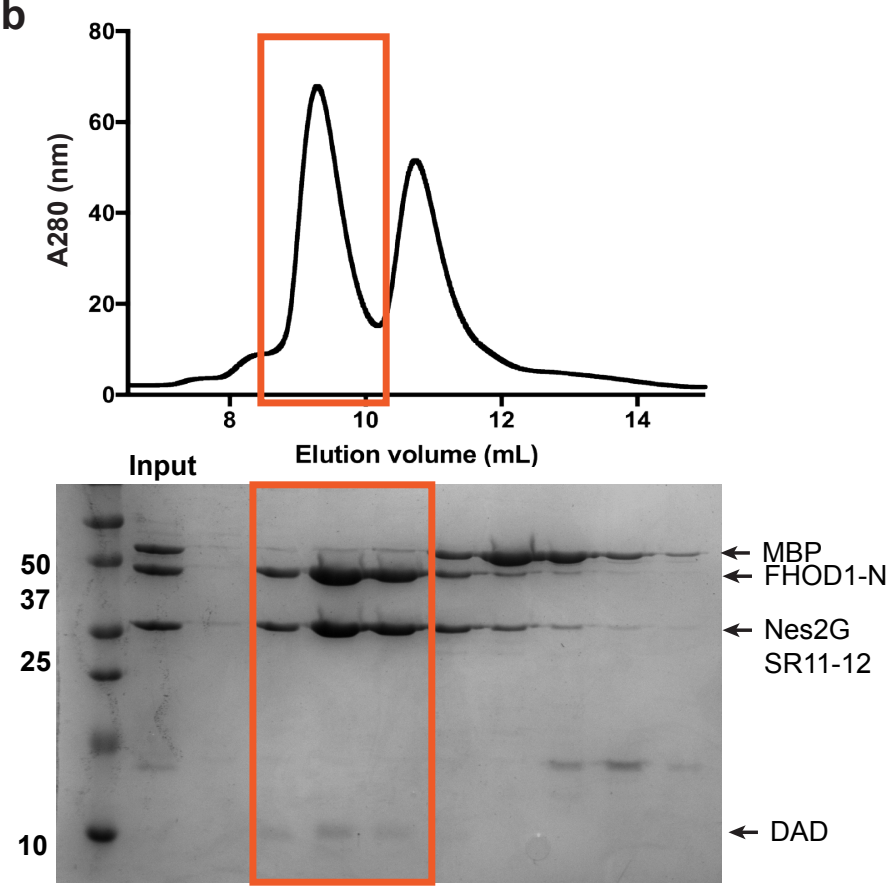
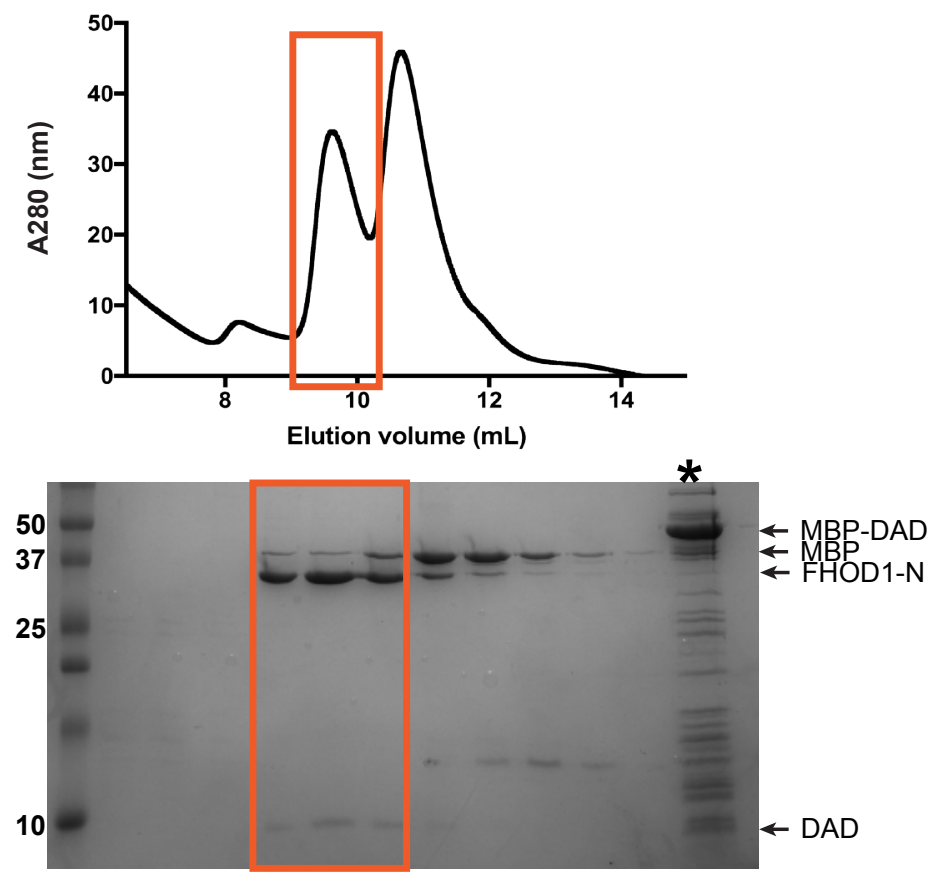


\section{Fiqure 8}

bioRxiv preprint doi: https://doi.org/10.1101/2020.06.19.161299; this version posted June 20, 2020. The copyright holder for this preprint (which was not certified by peer review) is the author/funder, who has granted bioRxiv a license to display the preprint in perpetuity. It is made available under aCC-BY 4.0 International license.

a

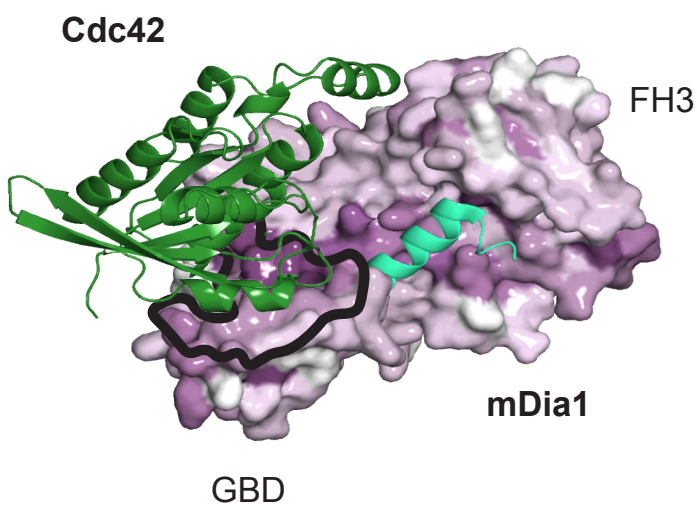

High

Low

Conservation

b

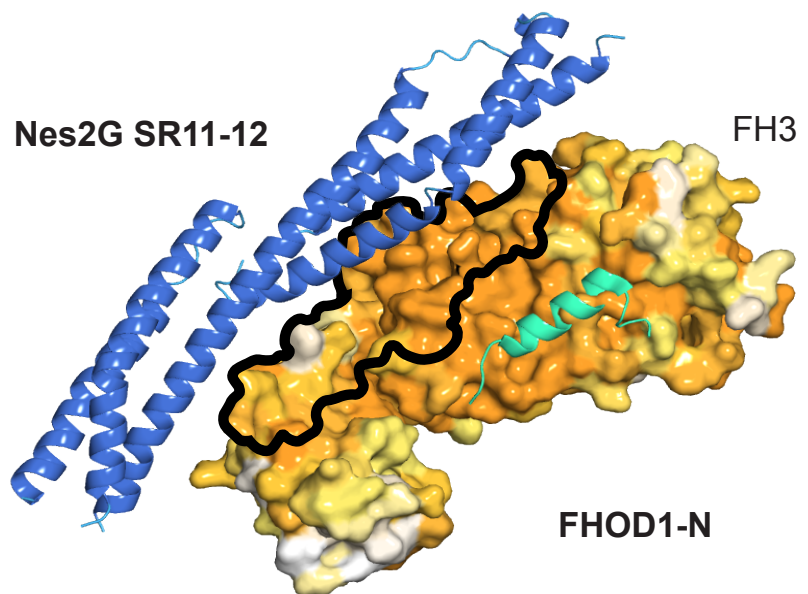

SRBM

High

Low

Conservation 


\section{Figure 9}

bioRxiv preprint doi: https://doi.org/10.1101/2020.06.19.161299; this version posted June 20, 2020. The copyright holder for this preprint (which was not certified by peer review) is the author/funder, who has granted bioRxiv a license to display the preprint in perpetuity. It is made available under aCC-BY 4.0 International license.

a

Nesprin2G

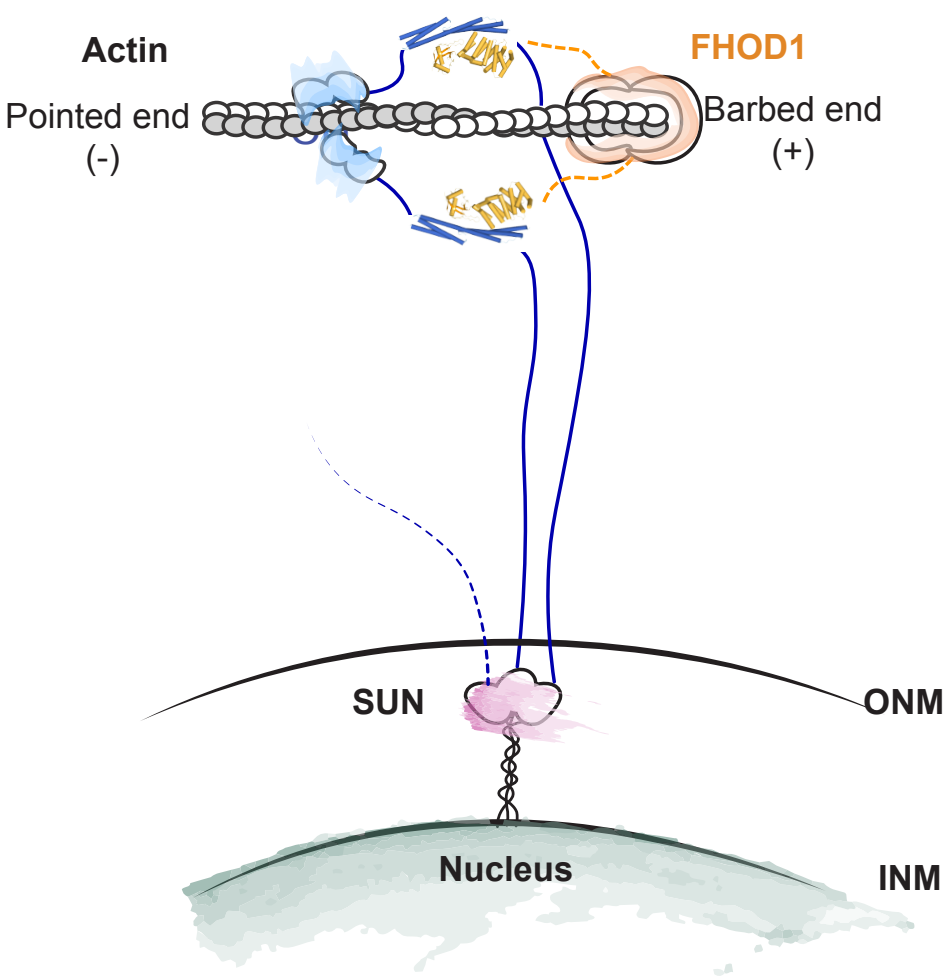

b

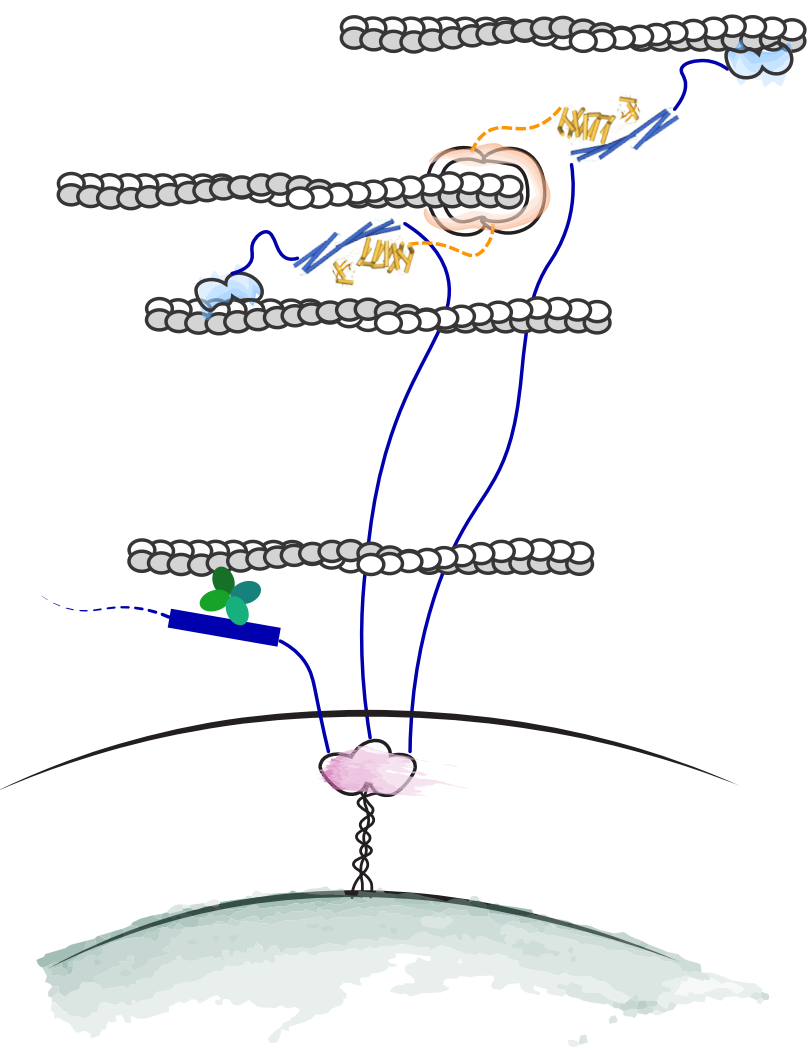

\section{Legend}

FHOD1-N-Nes2G SR11-12 complex

(C) FHOD1-FH2 domain

Nes2G SR51-53 